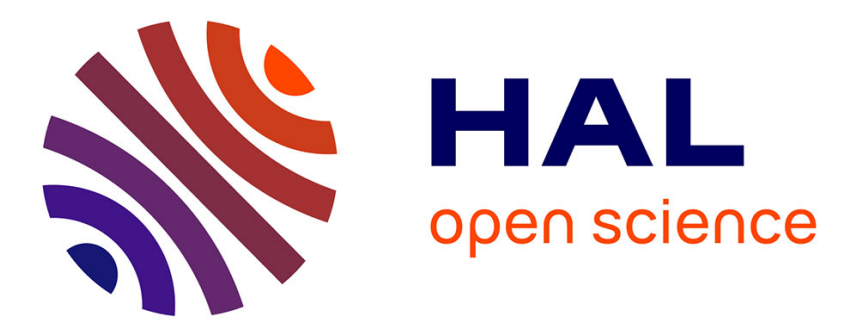

\title{
Effects of dipolar interactions on linear and nonlinear optical properties of multichromophore assemblies: A case study
}

Francesca Terenziani, Olivier Mongin, Claudine Katan, Kumar Goud Bhatthula, Mireille Blanchard-Desce

\section{To cite this version:}

Francesca Terenziani, Olivier Mongin, Claudine Katan, Kumar Goud Bhatthula, Mireille BlanchardDesce. Effects of dipolar interactions on linear and nonlinear optical properties of multichromophore assemblies: A case study. Chemistry - A European Journal, 2006, 12 (11), pp.3089-3102. 10.1002/chem.200500910 . hal-00517116

\author{
HAL Id: hal-00517116 \\ https://hal.science/hal-00517116
}

Submitted on 15 Sep 2010

HAL is a multi-disciplinary open access archive for the deposit and dissemination of scientific research documents, whether they are published or not. The documents may come from teaching and research institutions in France or abroad, or from public or private research centers.
L'archive ouverte pluridisciplinaire HAL, est destinée au dépôt et à la diffusion de documents scientifiques de niveau recherche, publiés ou non, émanant des établissements d'enseignement et de recherche français ou étrangers, des laboratoires publics ou privés. 


\title{
Effects of Dipolar Interactions on Linear and Nonlinear Optical Properties of Multichromophoric Assemblies: a Case Study
}

\author{
Francesca Terenziani, ${ }^{[a]}$ Olivier Mongin, ${ }^{[a]}$ Claudine Katan, ${ }^{[a]}$ Bharath \\ Kumar Goud Bhatthula, ${ }^{[\mathrm{a}]}$ and Mireille Blanchard-Desce ${ }^{*[\mathrm{a}]}$
}

Dedicated to the memory of Prof. Rüdiger Wortmann

\begin{abstract}
The issue of inter-chromophoric interactions in flexible multidipolar structures for nonlinear optics is addressed through the combined experimental and theoretical study of two series of one- , two- and three-chromophoric systems where identical push-pull chromophores are assembled via covalent and flexible linkers in close proximity. The photophysical and NLO properties (quadratic hyperpolarizability) of the multichromophoric systems are investigated and compared to those of the monomeric chromophores. Multimers possess larger dipole moments than their monomeric analogues, demonstrating that the dipolar subchromophores self-orientate within the multimeric structures. This effect is found to depend on the sub-chromophoric distance in a non-trivial manner, confirming that molecular engineering of such flexible systems is more complex than in completely geometrically controlled systems. EFISHG measurements conducted in solution reveal increased figures of merit as compared to their monomeric analogue. This effect is found to increase with the number and polarity of the individual sub-chromophores in the nanoassembly and the spacing between dipolar sub-chromophores.

Experimental results are interpreted through a theoretical model for interacting polar and polarisable chromophores. The properties of multidipolar assemblies are shown to be related to the relative orientation of chromophores, which is imposed by interchromophore interactions. The supramolecular structure is thus a result of self-organisation. The proposed theoretical model is also exploited to predict the properties of multichromophoric structures made up by more polar and polarisable push-pull chromophores, showing that stronger interchromophoric interactions can heavily affect the individual optical responses. This suggests new routes for engineering highly NLO responsive multichromophoric systems.
\end{abstract}

Keywords: chromophores, multichromophoric systems, nonlinear optics, self-organisation, theoretical models.

[a] Dr. F. Terenziani, Dr. O. Mongin, Dr. C. Katan, Dr. B. K. G. Bhatthula, Dr. M. Blanchard-Desce Synthèse et ElectroSynthèse Organiques (CNRS, UMR 6510), Institut de Chimie

Université de Rennes 1, Campus Scientifique de Beaulieu, Bât 10A

F-35042 Rennes Cedex (France)

E-mail: mireille.blanchard-desce@univ-rennes1.fr 


\section{Introduction}

Molecular materials are among the most promising candidates for advanced applications in the field of electronics ${ }^{[1]}$ and photonics. ${ }^{[2,3]}$ Also organic probes exhibiting high nonlinear optical (NLO) responses attract much attention in the field of biological imaging. ${ }^{[4]}$ The search for good candidates for these applications relies both on enhancing the response at the molecular level and on the design and elaboration of supramolecular structures having optimised responses, by taking advantage of symmetry and environmental effects. As the synthetic approach evolves from the molecular to the supramolecular level, theoretical and interpretative models are needed to guide the design at all stages. This is a critical issue not only because real-world applications often concern condensed phase systems ranging from solid state devices to soft condensed matter (including biological systems), in which the individual molecular entities will interact, but also on a more fundamental vein. As a matter of fact, while structure-properties relationships are quite actively and successfully investigated at the molecular level, ${ }^{[5]}$ supramolecular structure-property relationships are instead an interesting open problem, which deserves further analysis. ${ }^{[1,6,7]}$

A great variety of structures can be generally classified as "supramolecules", in spite of their possible different nature, ranging from crystals to films to multimolecular size-controlled assemblies to aggregates and multibranched or dendritic buildings. But all these architectures share the basic ingredient of being characterized by interactions between the building "molecular bricks". These interactions can be electrostatic in nature, origin from orbital overlaps, or even involve active connectors between the components. While a lot of experimental work has been devoted to the study of supramolecules, ${ }^{[6]}$ interpretative models are still scanty and relevant only to a few specific types of interacting systems.

A seminal theoretical work on the role of intermolecular interactions on the second-order optical properties of chromophoric molecular assemblies dates back already to more than ten years ago, ${ }^{[8]}$ demonstrating that the hyperpolarisabilities of $p$-nitroaniline dimers and trimers strongly depend on the relative molecular orientation of the chromophores and on intermolecular chromophore-chromophore interactions. This result, confirmed by several other contributions, ${ }^{[9,10]}$ is an important one and suggested some guide-lines for the optimized design of chromophoric assemblies with large hyperpolarisabilities. ${ }^{[11]}$

But up to now, the still open problem is the ability to predict the properties of a supramolecular architecture starting from the properties of its building blocks. The benefit of 
such a bottom-up approach would be considerable, giving the possibility of taking advantage of the acquired knowledge on molecular properties, and opening the way to the design of knowledge-based materials. Ab initio methods ${ }^{[12]}$ or semiempirical calculation techniques $^{[13,14]}$ provide precious tools for such aim, but at the expense of increased computational effort with the size of the system, especially when excited states, solvent or vibrational effects become important. In this respect, the study and modelling of size-limited and geometry-controlled molecular assemblies not only is important for the intrinsic properties of these structures, but also is a valid playground for the modelling of supramolecular interactions and the test of the proposed models. As a matter of fact, these assemblies have the basic ingredients of larger and more complex structures, with the advantage of being particularly suitable from the modelling point of view.

Simple models, based on a few states ${ }^{[15-17]}$ and on the choice of well focused interactions ${ }^{[18]}$ are also of great importance. These are, for example, the basic ingredients of the most widely used approach for interacting molecules: the excitonic model. ${ }^{[19]}$ This picture is apparently oversimplified, but it works well in describing the properties of aggregates of molecules interacting via their transition dipole moments, ${ }^{[20]}$ and it has also been successfully applied to model multipolar structures for NLO, in the case of weak interactions. ${ }^{[21]}$ However the very same model proves inadequate for strongly interacting dipolar entities, ${ }^{[22-24]}$ which is often the case in architectures optimized for second or third order NLO. In some cases also the presence of intermolecular interactions non electrostatic in nature (e.g. exchange interactions) is source of deviations from the excitonic predictions. ${ }^{[25-27]}$

In general, many supramolecular structures show enhanced NLO responses, but interpretative models have not often been applied or sufficiently tested. However there have been several (experimental) studies conducted on different multichromophoric systems that show that interchromophoric interactions can play a significant role. In particular, increased second harmonic generation figures of merit for multichromophoric buildings have been reported in the literature. ${ }^{[28-31]}$ For example, D- $\pi$-A functionalised calix[4]arenes showed up to 2.5 times amplified figures of merit (per sub-chromophore) compared to the corresponding reference compounds. ${ }^{[32]}$ A striking example of exaltation of the figure of merit is given by a chromophore-functionalised polymer, showing a 35-fold response per sub-chromophore with respect to the free chromophore. ${ }^{[33]}$ In those cases, the exaltation of the response was mainly due to a high degree of alignment of the functionalising chromophores: the hyperpolarisability of the supramolecular structures could well be interpreted through the oriented-gas model, even if for the polymer case a great contribution to the global dipole moment is given by the 
main polymeric chain. ${ }^{[33]}$ Other examples are reported where the response of multichromophoric assemblies shows small ${ }^{[34]}$ or more sizeable deviations ${ }^{[35,36]}$ from additive behaviour. These effects were ascribed to dipole-dipole coupling between sub-chromophores in functionalised cyclodextrines ${ }^{[34]}$ or dendrimers, ${ }^{[36-38]}$ or also to possible $\pi-\pi$ interactions in the case of functionalised calix[4]arenes. ${ }^{[35,39]}$ Another striking example of the role of interchromophoric interactions is observed for cyclophane derivatives where two dipolar push-pull stilbenes, that are maintained in a forced relative orientation, are found to interact via through-space interactions. ${ }^{[40,41]}$ All these studies point to the importance of structural parameters (geometry, distance, nature of the chromophores) in multichromophoric buildings, calling for further analysis.

In order to address the problem of interaction effects on the properties of molecular multidipolar assemblies, we have studied two series of homologue products, obtained by grafting one, two or three active dipolar chromophores to a central phenyl core. In these model systems where push-pull chromophores are assembled via covalent flexible linkers within close proximity, dipolar interactions between individual sub-chromophores are expected to influence both the conformation and the optical properties of the multichromophoric nanoassemblies. In this perspective, chromophores with high dipole moment were selected. Such flexible multimers series provide valuable models for the investigation of confinement effects on the linear and nonlinear optical (NLO) responses of push-pull chromophores. In this paper we report their synthesis, their spectroscopic characterization (absorption and fluorescence, solvatochromism) and the experimental determination of their second order NLO properties. Complementary to previously reported (experimental and theoretical) studies our goal has been to investigate how i) the number of sub-chromophores, (ii) the nature of the dipolar sub-chromophores (i.e. both its polarisation and polarisability) and (iii) the geometrical constraints (such as fixed distance between specific parts of sub-chromophores) may affect the "supramolecular" effect.

The linear and nonlinear optical properties of the two series are interpreted through a recently proposed model which describes the responses of interacting polar molecules starting from the properties of the single chromophore. ${ }^{[18,42]}$ We demonstrate that interactions between sub-chromophores are responsible for their arrangement within the "supramolecules", thus fixing the responses of the assemblies. For the studied series, this is true even though interchromophore distances are too large to sizeably affect the individual responses of each constituent sub-chromophore. We also show, through simulations, that at shorter distances or for more polar and/or polarisable sub-chromophores, the geometry and the optical responses 
of the multichromophoric assemblies are highly and nontrivially affected by sub-chromophore interactions. This opens the route towards cooperative multichromophoric assemblies where the NLO responses of the individual sub-chromophoric components would also be enhanced resulting in much more efficient molecular assemblies.

\section{Results}

Model systems: Two series of size-controlled multichromophoric assemblies were synthesised by functionalising a central phenyl core with two or three push-pull chromophores characterised by the same electron-releasing amino moiety and by two different electron-withdrawing entities: a nitrophenyl moiety group (Series I, Figure 1) or a dicyanovinyl moiety (Series II, Figure 2). The chromophores were grafted to the central core through flexible connectors chosen as "passive" spacers between the active chromophores. This allows to single out electrostatic forces as the source of intermolecular interactions. In addition the chosen spacers maintain spatial proximity between sub-chromophores thus allowing for through-space dipole-dipole interaction to take place while providing the required flexibility allowing orientational freedom.

Three types of dimers were studied by grafting the two sub-chromophores in ortho or meta or para positions on the central core. This allows modulating the distance between subchromophores and studying the effect of interchromophore distance on the properties of the multichromophoric assemblies. The spectroscopic and second order NLO properties of the dimers and trimers in each series have been studied and compared with the properties of the corresponding monomeric model compounds obtained by hanging a single unity to the same central core and through the same connector. The effects of intermolecular interactions on the geometry and properties of the assemblies have been deduced and rationalized.

Synthesis: Both graftable chromophoric building blocks $\mathbf{3}$ and $\mathbf{6 b}$ were synthesized from the same precursor, i.e. aldehyde $\mathbf{1}$ (Scheme 1). NLO-phore 3 was prepared by Knoevenagel condensation of $\mathbf{1}$ with malononitrile (2), whereas $\mathbf{6 b}$ was obtained in a three-step sequence, involving protection of the alcohol function of $\mathbf{1}$ as an acetal, Horner-Wadsworth-Emmons condensation with phosphonate 5, and deprotection of the acetal (Scheme 1). By esterifying both alcohols (6b and $\mathbf{3}$ ) with acyl chlorides 8a-c and 9, two series of di- and trichromophoric 
assemblies (I and II, respectively) were obtained. Monochromophoric models I-1 and II-1 were also obtained by reaction of $\mathbf{6 b}$ and $\mathbf{3}$ with benzoyl chloride (Scheme 2).

Linear optical properties: The UV-visible absorption and the fluorescence spectra of I-1, I2O, I-2P and $\mathbf{I - 3}$ have been recorded in toluene, chloroform $\left(\mathrm{CHCl}_{3}\right)$ and acetone. Spectra of II-1, II-2M, II-2P and II-3 have been recorded in toluene, $\mathrm{CHCl}_{3}$ and dimethylsulfoxide (DMSO). A fourth solvent (triacetin) has been used for I-1. The absorption and emission solvatochromic behaviour of I-1 and of II-1 are reported in Figure 3 and Table 1, while the solvatochromism of dimers and trimers is available as Supporting Information. The solvatochromic behaviour of each compound inside a series is nearly the same, characterized by a red-shift of both absorption and fluorescence bands at increasing solvent polarity, the effect being greater for fluorescence spectra.

Figure 4 compares the spectra of the products of Series I (panel a) and of Series II (panel b) in $\mathrm{CHCl}_{3}$. Spectra in the other solvents are accessible as Supporting Information. Slight effects on absorption and fluorescence bands are recognizable as due to sub-chromophoric interactions. In particular, a small blue-shift is observed going from the monomer to the multimers in the case of both series, whereas a decrease of oscillator strength (per subchromophore) is observed in the case of series II (see also Table 2). The decrease of the maximum extinction coefficient is accompanied by a slight broadening of the spectrum. This (inhomogeneous) broadening when going from the monomer to the trimer is most probably linked to the larger conformational disorder in the multimers.

Fluorescence quantum yields were measured by using fluorescein $0.1 \mathrm{~N} \mathrm{NaOH}$ as a reference $\left(\phi_{\mathrm{ref}}=0.90\right) .{ }^{[43]}$ Products of Series I have significant quantum yields in toluene, varying from about $80 \%$ for the monomer down to about $20 \%$ for the trimer. In $\mathrm{CHCl}_{3}$ and acetone the quantum yields are very weak (about 3\% and 1\%, respectively) for all the products of the series. Series II has very weak quantum yields, always lower than $1 \%$.

Dipole moments: Dipole moments $\mu$ of all the products of Series I and of II-1 were determined from dielectric and refractive index measurements conducted in $\mathrm{CHCl}_{3}$, by means of the Debye formula. ${ }^{[44]}$ The measured values are reported in Table 4. II-1 has a larger dipole moment than I-1, even if the length of the dipole can be estimated as shorter. This suggests a more pronounced charge-transfer character of II-1 in the ground state, as probably due to the stronger electron-withdrawing character of the dicyanovinyl group with respect to the nitro group. 
Values for Series I allow to conclude that all the multimers possess a high dipole moment (from 12 to $15 \mathrm{D}$ ), which indicates a non-random spatial organization of the subchromophores grafted to the central core. In particular, by assuming a V-shaped configuration for the dimers, and a calyx-like shape for the trimer (see Figure 5), the angle formed by each sub-chromophore with the main symmetry axis of the assembly can be estimated. With the assumption that the dipole moment of each sub-chromophore in the assembly is not highly affected by intermolecular interactions, the following angles are calculated: $45^{\circ}$ for $\mathbf{I - 2 O}, 35^{\circ}$ for $\mathbf{I}-\mathbf{2 M}, 40^{\circ}$ for $\mathbf{I}-2 \mathbf{P}$ and $55^{\circ}$ for $\mathbf{I}-3$.

Second order nonlinear properties: The second order nonlinear optical responses of all the products were measured in $\mathrm{CHCl}_{3}$ through the electric field induced second harmonic generation (EFISHG) technique, operating at $1.9 \mu \mathrm{m} .{ }^{[45]}$ This method, which can be used only in the case of solutes possessing a non-vanishing dipole moment, allows accessing the product $\mu \beta(2 \omega)$, where $\beta$ is the vector component of the $\beta$ tensor in the direction of the dipole moment $(z)$, usually called $\beta_{z}$. In the following all the reported and discussed $\beta$ values correspond to this quantity, except where explicitly specified. The $\beta(2 \omega)$ values can be calculated as long as the dipole moment values are known. The corresponding static values, $\beta(0)$ can also be estimated by the use of the two-state model, ${ }^{[46]}$ as follows:

$$
\beta(0)=\frac{\left(\omega_{\mathrm{abs}}^{2}-\omega^{2}\right)\left(\omega_{\mathrm{abs}}^{2}-4 \omega^{2}\right)}{\omega_{\mathrm{abs}}^{4}} \beta(2 \omega)
$$

The EFISHG figure of merit $\mu \beta(0)$, is then accessible. All results are reported in Table 4, according to the $X$ convention as defined in Ref. ${ }^{[47]}$. The multichromophoric strategy leads to an amplification of the figure of merit up to a factor 4 for the trimer of Series II, with a net gain with respect to the increased molecular weight. Indeed all multimers show higher normalized figure of merit $\mu \beta(0) / M$ than the corresponding momoner. Interestingly, the enhancement seems to increase with the number of sub-chromophores in the nanoassembly and with increasing polarity of the sub-chromophores. 


\section{Discussion}

Solvatochromism: The solvatochromic behaviour of all the studied products is typical of transitions involving an excited charge-transfer state having a larger dipole moment than the ground state. ${ }^{[48]}$ As a matter of fact, a rough assessment of the value of $\Delta \mu$ (the difference between the dipole moment of the excited- and of the ground state) can be derived from the $\beta(0)$ value by using the two-level model, starting from the measured values of the transition frequency and dipole moment. ${ }^{[46]}$ For the two monomers, this estimate leads to a $\Delta \mu$ value of 9.1 and 3.6 D for I-1 and II-1, respectively. This also confirms the guess of a higher charge transfer character for the ground state of II-1 with respect to I-1.

The spectra of II-1 can be reproduced by the use of the two-state model + Holstein coupling to an effective molecular vibration + solvation interaction. The model is detailed in Ref. ${ }^{[49]}$ and summarised in the Experimental Section. The fit allows to estimate the model parameters: the energy difference between the neutral and the zwitterionic basis states $\left(2 z_{0}\right)$, the mixing matrix element $(-\sqrt{ } 2 t)$, the vibrational frequency $\left(\omega_{v}\right)$ and the vibrational relaxation energy $\left(\varepsilon_{v}\right)$ of the effective coupled mode. In order to reproduce the spectra, Gaussian band-shapes have been chosen, of half-width at half-maximum $\Gamma$. Another parameter is needed to describe the solvent polarity: the solvent relaxation energy $\left(\varepsilon_{o r}\right)$, which is the only parameter that is allowed to change from one solvent to another. Spectra of II-1 can be reproduced by fixing the parameters reported in Table 3 (second row). In order to quantitatively reproduce the absorption intensity, the value $\mu_{0}=20.5 \mathrm{D}$ has been fixed for the dipole moment of the zwitterionic basis state. The fit of the spectra is reported in Figure $6 \mathrm{~b}$. These parameters correspond to a degree of charge transfer $(\rho)$ in the ground state ranging from 0.15 in toluene to 0.16 in DMSO.

The model, when allowed to fully account for molecular polarisability at all orders, also estimates different degrees of charge transfer for the molecule when slow coordinates (vibrational and solvation degrees of freedom) are in equilibrium with the electronic distribution relevant to the ground or to the excited state. ${ }^{[49,50]}$ This mechanism of interaction is typically non-linear since the configuration of slow degrees of freedom depends on the molecular electronic distribution, which in turn is affected by the configuration of slow degrees of freedom. This leads to the following degrees of charge transfer in the FranckCondon ground state $(\rho *)$, i.e. relevant to the fluorescence process: $0.20,0.22,0.25$ in toluene, $\mathrm{CHCl}_{3}$ and DMSO, respectively. This means that for the geometry relevant to the 
fluorescence process, the molecule has a more polar and polarisable ground state than for the geometry relevant to the absorption process.

The fit of the spectra of I-1 is somewhat more difficult. Spectra in Figure 3a show that the Stokes-shift is very large even in an almost non-dipolar solvent like toluene. This suggests the presence of another coupled degree of freedom, different from a molecular vibration and from the solvation coordinate. Due to the non rigid structure of the relevant chromophore, this coordinate is probably a conformational degree of freedom, so that fluorescence likely stems from a so-called twisted intramolecular charge transfer state. This hypothesis is indirectly confirmed by spectra collected in triacetin, a very viscous solvent (blue lines in Figure 3a): in fact, even if triacetin is more polar than $\mathrm{CHCl}_{3}$, the Stokes-shift in this solvent is lower than in chloroform, suggesting that the high viscosity hinders to some extent conformational reorganisation in the excited state. Conformational coordinates are different in nature from molecular vibrations or from solvation degrees of freedom: while these last coordinates affect diagonal terms in the Hamiltonian, a conformational coordinate modulates the mixing matrix element (the charge transfer integral) between the basis states. ${ }^{[51]}$ This type of coupling was already modelled for successfully describing the spectra of phenol blue, another flexible chromophore. ${ }^{[49]}$ Here we use that extension of the model, by introducing the relevant additional parameter: the conformational relaxation energy, $\varepsilon_{c}$. The first effect of this coupling is an increased Stokes-shift, due to the fact that the equilibrium conformational coordinate is different for the ground- and the excited state. In addition, a Boltzmann distribution of conformations must be accounted for at finite temperature due to the fact that the conformational coordinate is characterised by very low frequency (typically in the far infrared-microwave region), leading to an additional inhomogeneous broadening of the absorption and emission bands.

By fixing the parameters in Table 3 (first row), the spectra of I-1 in all solvents can be reproduced. ${ }^{[52]}$ The value of $\mu_{0}$ has been fixed to $33 \mathrm{D}$. The corresponding degrees of charge transfer are lower than for II-1, being of the order of 0.05 in all the solvents. This is again a confirmation of the weaker electron-withdrawing power of the nitro group with respect to the dicyanovinyl one. As a matter of fact, also the solvatochromic effect is smaller in absorption and larger in fluorescence in Series I than in Series II, pointing to the more neutral nature of the chromophore in Series I.

Interchromophoric effect: Interchromophore interactions for the two studied series are purely electrostatic in nature. In fact the spacers connecting each sub-chromophore to the 
central phenyl core are "passive", i.e. they prevent conjugation to extend from one subchromophore to another. Moreover the distance that can be estimated between the grafted sub-chromophores is large enough to hinder overlap between molecular orbitals of different sub-chromophores. In addition, in both cases interactions are weak, as demonstrated by the small variations of absorption and fluorescence spectra when going from the monomer to the dimers to the trimer. This is due to their strongly dominating neutral nature and also to the molecular architecture. In the chosen multichromophoric structures, chromophores are linked to the central core through one end, while the other end is completely free, so that the subchromophores have the possibility to adopt the relative orientation that minimises repulsive interactions. This leads to self-non-centrosymmetrically organised structures as proven by the large dipole moments measured even in the case of trimers or para-dimers. This intrinsic asymmetry results in significant second order nonlinearity, demonstrating than even in the weak interaction case - i.e. when the individual optical responses of the sub-chromophores within the nanoassembly are not much affected - the dipolar interchromophoric interactions plays an important role by controlling their relative orientation, and thus the overall architecture of the nanoassembly.

By using a simple electrostatic model, it is possible to plot the dependence of the interaction energy on the angle formed by the sub-chromophores. The dipole approximation could be used, but it would not permit to distinguish cases in which the chromophores have different lengths (i.e. here to distinguish between Series I and Series II). Hence, here we prefer associating +/- charges to the donor/acceptor ends, and model the interactions by estimating the interchromophore distance (at the donor ends) and the length of each chromophore (between donor and acceptor groups). We assume a $\mathrm{V}$-shaped configuration for dimers $\left(\mathrm{C}_{2 \mathrm{v}}\right.$ charge symmetry) and a calyx-like shape for trimers $\left(\mathrm{C}_{3 \mathrm{v}}\right.$ charge symmetry), as sketched in Figure 5. We fix the distance between the donor ends at 13, 15 and $17 \AA$ respectively for ortho, meta and para positions, and impose a length of 10 and $8 \AA$, respectively, for the chromophore in Series I and II. By minimising the electrostatic energy of interaction, we predict the following angles formed by each sub-chromophore with respect to the principal symmetry axis of the assembly: $46^{\circ}$ for $\mathbf{I}-\mathbf{2 O}, 41^{\circ}$ for $\mathbf{I}-\mathbf{2 M}, 38^{\circ}$ for $\mathbf{I}-2 \mathbf{P}, 55^{\circ}$ for I-3; $40^{\circ}$ for II-20, $36^{\circ}$ for II-2M, $33^{\circ}$ for II-2P, $47^{\circ}$ for II-3. The deviation between the two series results from the difference in chromophore lengths. The estimated angles compare well with the angles derived from the experimental dipole moments values of (multi)chromophores of Series I. ${ }^{[53]}$ This simple procedure is already a clear demonstration that interchromophore 
electrostatic interactions determine the relative orientation of sub-chromophores and hence the supramolecular conformation of the assembly.

Here it is worthwhile to stress that the strength of the electrostatic interaction that can be estimated between sub-chromophores in the assemblies is at least one order of magnitude higher than the interaction between each sub-chromophore and the static electric field applied for the EFISHG experiment (typically of the order of $10^{6} \mathrm{~V} / \mathrm{m}$ ). For this reason the geometry of the multichromophores can be considered as independent of the applied electric field, and the nanoassemblies can be considered as independent units interacting with the field itself via their global dipole moment.

To further validate the proposed approach, in the following we will show spectra calculated for dimers and trimers, as well as the calculated $\beta$ values for all the products of the two series. The extension of the two-state Mulliken model to describe interacting chromophores has been recently proposed. ${ }^{[18,54]}$ This approach is different from the standard excitonic model since it allows to calculate the properties of the "supramolecule" by starting from the parameters estimated for the isolated (or solvated) chromophoric unit and from the geometry of the assembly. This is due to the fact that the molecular (hyper)polarisability is fully accounted for, so that environmental effects are self-consistently taken into account. Another noteworthy difference with respect to the standard excitonic approach is the fact that all electrostatic interactions are considered, not only those arising from the coupling of the transition dipole moments, this latter approximation being strictly valid only for non-dipolar molecules. This model for interacting polar and polarisable chromophores has been further extended to account for molecular vibrations and solvation, ${ }^{[42,55]}$ to allow for comparison with experimental measurements. Along these lines calculations reported hereafter have been performed.

Figure 7 shows spectra calculated for the products of Series II. For the multimers, the same parameters deduced for the monomer have been used, with the additional geometrical parameters, i.e. interchromophore distances and angles, as obtained by minimising the interactions. In this case interactions are weak (interchromophore distances are about twice the chromophore length), so that multichromophoric effects are also weak: sub-chromophore polarity only varies of an amount of 1 and $2 \%$, respectively, for the trimer of Series I and II with respect to the monomeric analogue. The main characteristics of the spectra are reproduced, such as the small blue-shift of the band and the small decrease of oscillator strength from the monomer to the multimers. Experimental spectra of dimers and trimer are somewhat additionally broadened, but this can be easily associated to the higher geometrical 
disorder for the multimers. These calculated spectra are a confirmation that the fixed geometrical parameters are reliable.

A further test of the chosen parameters and of the proposed interpretation is given by the comparison of experimental and calculated $\beta$ values. Calculated $\mu \beta(2 \omega)$ and $\beta(2 \omega)$ are reported in the last two columns of Table 4 . The agreement is not quantitative with respect to the individual values, but the trend inside each series is very well reproduced, as shown by the ratios between the response of the multimers and the response of the corresponding monomer (values in parentheses in Table 4). The reason for the non quantitative agreement of the individual values is mainly due to the evaluation of the dipole moment in the ground- and in the excited state. Actually, both the transition energy and the transition dipole moment are very well reproduced (as demonstrated by the good agreement between experimental and calculated spectra). On the contrary, the ground state dipole moments fixed by the chosen molecular parameters highly underestimate the measured values: $1.6 \mathrm{D}$ and $3.2 \mathrm{D}$ calculated for I-1 and II-1, respectively, vs. the experimental 8.7 and 9.7 D values. This quite large discrepancy is somehow surprising, since the calculated (permanent) dipole moments allow correctly reproducing the solvatochromic behaviour of all the products. One of the possible reasons may be related to the fact that the dipole moment values estimated from the fit of the spectra are related to the polarisable (and hence responsive) part of the skeleton only, while the measured ones correspond to the total ones. As a matter of fact, the contribution of the connecting spacers to the total dipole moment can be non negligible, and their contribution is more important the smaller is the dipole moment of the grafted chromophore (more important for Series I than for Series II). The same problem concerns also the excited state, for which calculations overestimate the dipole moment. Despite these discrepancies, we observe a good agreement between the experimental and calculated values of the ratio between the nonlinear responses of the multimers and of the corresponding monomer (Table 2).

The sizeable increase in the $\beta$ value from dimer ortho to dimer meta to dimer para (Series I) indicates that the distance between sub-chromophores influences the self-arrangement of the dipolar sub-chromophores within the nanoassembly and thus its second-order optical responses. The non random spatial self-organisation results in an increase of the $\beta$ response from the monomer to the multimers, by a factor of the order of 1.5-2. This, in combination with the increased dipole moment in the dimers and trimers, leads to an amplification of the figure of merit $\mu \beta$ up to a factor 4 . The amplification is more important for Series II than for Series I because of smaller angles imposed by interchromophore interactions, as resulting 
from the difference in length of the corresponding monomers. It is also interesting to note that for both series the trimeric compound shows improved performance as compared to the dimeric analogues. Hence, for the same interchromophore distance (i.e. when comparing trimers with meta dimers), the multichromophoric strategy provides improvement of the seecond order NLO response for increasing number of sub-chromophore in the nanoassembly.

\section{Conclusions and perspectives}

In this paper we addressed the properties of multidipolar structures by experimental measurements of linear and nonlinear optical properties, and through a recently proposed theoretical model for interacting polar and polarisable molecules. Multichromophoric assemblies were obtained by grafting one, two or three active chromophores on a central passive core. In the studied cases, responses of multimers are almost additive, in the sense that an oriented-gas model can account for the properties of the assemblies. But, more importantly, we demonstrated that the relative orientation of sub-chromophores is dictated by intermolecular interactions, so that interactions are the driving force in determining the properties of the assembly, even when they are fairly weak. Inter-branch interactions are thus responsible for a non-random self-arrangement of the sub-chromophores grafted to the central core, leading to an increased dipole moment of the supramolecular assemblies with respect to the monomeric analogue. The increase in the dipole moment has a twofold advantage. In fact it is responsible for a better molecular orientation and thus a higher value of the global order parameter, resulting in possibly larger bulk susceptibilities. But also at the microscopic level this effect can lead to increased figures of merit $\mu \beta$ per sub-chromophore: in our case an increase up to $30 \%$ (for compound II-3) is observed.

Quite a few results in the literature suggest that strong interactions between chromophores can lead to large deviations from simple additive contributions of active chromophores. The analysis we presented here represents a case study, relevant to the limit of weak interactions; but the adopted model can be exploited to predict the properties of strongly interacting chromophores, since it fully takes into account the molecular polarisability. As a matter of fact, dipolar chromophores are highly responsive to any change in the environment (as demonstrated by their pronounced and non-trivial solvatochromism), so that the properties of multichromophoric systems are expected to strongly depend on relative intermolecular

orientation and distance. ${ }^{[8,13,18]}$ These "environmental" effects will be larger the stronger are 
the interactions and the more polarisable are the chromophores. ${ }^{[18]}$ In Figure 8 we report two examples showing what is expected for more polar and polarisable interacting chromophores. The top panel in Figure 8 shows the figure of merit (as absolute value) calculated for a dimer (of symmetry $\mathrm{C}_{2 \mathrm{v}}$ ) of molecules being almost zwitterionic when isolated in solution. Parameters are relevant to the chromophore $\mathrm{C}_{16} \mathrm{H}_{33} \mathrm{Q}-3 \mathrm{CNQ}$, as reported in Ref. ${ }^{[56]}$. In this case, at intermolecular distance of about $10 \AA$ and at corresponding equilibrium intermolecular angle (about $42^{\circ}$ ) the response of the dimer is almost three times the response of the isolated molecule: this is due to the fact that polarisation effects sum up to oriented-gas effects in determining the properties. For this same dimer, a figure of merit 5 times larger than that of the monomer is expected for parallely oriented molecules at intermolecular distance of $8 \AA$ (without polarisability effects, the gain factor could not be larger than 4). The bottom panel in Figure 8 is relevant to push-pull chromophores being at the cyanine limit when isolated. This means that their first hyperpolarisability is vanishing. But, as due to intermolecular interactions, large SHG figures of merit can be obtained. This is a striking example of the importance of polarisability effects on the properties of interacting systems: even starting from non-responsive molecules, highly responsive assemblies could be achieved. Hence, the same model molecule, arranged in assemblies of different fashions (relative distance, orientation, ...) can behave in quantitative and qualitative different ways. Being able to correctly take into account all these ingredients in the design and synthesis of supramolecular structures in a knowledge-based (or bottom-up) approach will allow to tailor geometrical degrees of freedom as to maximise the desired responses. In this respect, we currently work on the engineering of multichromophoric systems made up by strongly polar and/or polarisable chromophores, as to exploit their self- or pre-arrangement as well as a possible self-improving mechanism of the desired property.

\section{Experimental}

Spectroscopic measurements: UV-visible spectra were recorded on a Jasco V-570 spectrophotometer on solutions ca. $10^{-5} \mathrm{M}$. Fluorescence measurements were performed on dilute solutions ( $c a .10^{-6} \mathrm{M}$ ) using an Edinburgh Instruments (FLS 920) spectrometer in photon-counting mode. For Series II, Raman emission lines of the solvent were subtracted to the emission signal. Fluorescence quantum yields were measured using fluorescein in $0.1 \mathrm{~N}$ $\mathrm{NaOH}$ as a standard (quantum yield $\phi=0.90) .{ }^{[43]}$ Solvents were of spectroscopic grade. All measurements were carried out at room temperature.

Dipole moment measurements: Permanent dipole moments were determined by means of a WTW dipolemeter (type DM01) made of a capacitance cell for liquids and a capacitancemeasurement electronic bridge. 
NLO measurements: $\beta$ measurements were performed using the electric field induced second harmonic generation (EFISHG) technique. ${ }^{[4]}$ The EFISHG experiment allows the determination of the mean microscopic hyperpolarisability $\gamma_{0}$ :

$$
\gamma_{0}=\gamma(-2 \omega, \omega, \omega, 0)+\mu \beta(-2 \omega, \omega, \omega) /(5 k T)
$$

The first term is the scalar part of the cubic hyperpolarisability tensor, whereas the second originates from the partial orientation of the permanent dipole moment $\mu$ in the static field. The orientational contribution is usually assumed to be the predominant component in the case of polar charge transfer molecules. The product $\mu \beta(2 \omega)$ is thus directly inferred.

EFISHG measurements were conducted with a Q-switched $\mathrm{Nd}^{3+}$ :YAG laser emitting pulse trains and operating with the first Stokes radiation, at $1.907 \mu \mathrm{m}$, of the YAG $1.064 \mu \mathrm{m}$ emission generated in an hydrogen Raman cell. These experiments were performed using, for each molecule, solutions of increasing concentration in chloroform. Measurements are calibrated relative to the pure solvent. The experimental accuracy does not exceed $5 \%$. The reported $\beta$ values follow the $X$ convention as defined in Ref. ${ }^{[47]}$.

Theoretical model and calculations: Push-pull chromophores are molecules made up of an electron-donor and an electron-acceptor group connected by a $\pi$-conjugated bridge. They are characterized by a low-energy transition (in the visible region) with high intensity, linked to a charge transfer from the donor to the acceptor moiety. For this reason they are usually and successfully described as resonating between two basis states: the neutral and the zwitterionic structure, a two-level model being enough for describing the basic physics of these molecules. The theoretical approach adopted in this paper is based on the two-state Mulliken model, ${ }^{[57]}$ extended to account for Holstein coupling to molecular vibrations, and for solvation interaction. For a single chromophore in solution the relevant Hamiltonian reads: ${ }^{\text {[50] }}$

$$
h=2 z_{0} \hat{\rho}-\sqrt{2} t \hat{\sigma}_{x}+\sum_{i}\left[\frac{1}{2}\left(\omega_{i}^{2} Q_{i}^{2}+P_{i}^{2}\right)-\sqrt{2 \varepsilon_{i}} \omega_{i} Q_{i} \hat{\rho}\right]
$$

where $z_{0}$ and $t$ are the parameters of the two-state model: $2 z_{0}$ is the energy difference between the neutral and the zwitterionic basis states and $-\sqrt{2} t$ is the mixing matrix element (charge transfer integral); $\hat{\rho}$ is the operator that counts electrons on the acceptor site; $\hat{\sigma}_{x}$ is one of the Pauli spin operators. The expectation value $\rho=\langle\hat{\rho}\rangle$ measures the weight of the zwitterionic structure in the ground state, and hence represents the molecular polarity. In fact, following Mulliken, a dipole moment $\mu_{0}$ can be associated to the zwitterionic basis state, neglecting all other contributions. In this way, the ground state dipole moment is given by $\mu_{0} \rho$, and the excited state dipole moment by $\mu_{0}(1-\rho)$. Transition energy and dipole moments are given, respectively, by: $\hbar \omega_{C T}=\sqrt{2} t / \sqrt{\rho(1-\rho)}$ and $\mu_{C T}=\mu_{0} \sqrt{\rho(1-\rho)}$.

In the above Hamiltonian the summation runs over coupled modes (of coordinate $Q_{i}$, momentum $P_{i}$ and frequency $\omega_{i}$ ), i.e. coordinates along which the potential energy surfaces relevant to the two basis states are displaced. The parameter $\varepsilon_{i}$ measures the relaxation energy of the relevant mode. Coupled modes can be molecular vibrations, or also a solvation coordinate (in the case of polar solvents). In this paper we reproduce experimental spectra by the use of a single coupled molecular vibration (of frequency $\omega_{v}$ and relaxation energy $\varepsilon_{v}$ ) and a solvation coordinate (whose relaxation energy is $\varepsilon_{o r}$ ). The frequency of the solvation degree 
of freedom (being very low, typically in the far-infrared/microwave region) is not needed to be fixed, since this mode can be treated as a classical coordinate. ${ }^{[58]}$ At finite temperature a Boltzmann distribution along this coordinate must be accounted for, that is the origin of inhomogeneous broadening of spectra in polar solvents. ${ }^{[49,58]}$ Along the vibrational coordinate, the potential energy surfaces relevant to the two basis states are chosen as harmonic and with the same frequency. But as a result of diagonalisation, potential energy surfaces are no more harmonic for the ground- and the excited state and they are softened and hardened, respectively. ${ }^{[58]}$ In the adiabatic approximation, the electronic problem corresponds again to a two-state problem, but with the parameter $z_{0}$ self-consistently renormalized: $z_{0} \rightarrow$ $z_{0}-\left(\varepsilon_{v}+\varepsilon_{o r}\right) \rho$ if slow degrees of freedom are in equilibrium for the ground state, and $z_{0} \rightarrow$ $z_{0}-\left(\varepsilon_{v}+\varepsilon_{o r}\right)\left(1-\rho^{*}\right)$ if slow degrees of freedom are in equilibrium for the excited state. ${ }^{[50,58]}$ The self-consistency corresponds to the system (hyper)polarisability. One of the consequences of the electronic polarisability is just the different degree of charge transfer $(\rho)$ in the case of different geometries of slow variables: a ground state polarity $\rho$ relevant to the absorption process; a ground state polarity $\rho^{*}$ relevant to the fluorescence process. This allows accounting for non specular absorption and fluorescence spectra. ${ }^{[49,50]}$

The vibrational problem is solved exactly (for the ground and the excited electronic state) on the basis of the harmonic oscillator of frequency $\omega_{v}$ centred at the relevant equilibrium position. ${ }^{[59]}$ The vibrational matrix is diagonalised on a truncated basis as large as to get convergence. ${ }^{[60]}$ As much as for semiempirical models, all the parameters are fixed as to best reproduce experimental spectral features. Spectra are calculated by associating to each vibronic transition a Gaussian lineshape.

For flexible chromophores another degree of freedom must be accounted for, describing conformational motion. Such a mode tunes the charge transfer integral, $-\sqrt{2} t$, and is characterised by a very low frequency (typically in the microwave region). The electronic Hamiltonian taking into account this mode reads: ${ }^{[49]}$

$$
h=2 z_{0} \hat{\rho}-\sqrt{2}(t+\Delta) \hat{\sigma}_{x}+\frac{\Delta^{2}}{\varepsilon_{c}}
$$

where $\Delta$ is the conformational coordinate, measuring the deviation of $t$ from its reference value, and $\varepsilon_{c}$ is the corresponding relaxation energy; the simple hypothesis that a harmonic potential is associated to this mode has been made. Although different in nature, the conformational coordinate can be treated along the same lines of the solvation degree of freedom, i.e. in the adiabatic approximation and in the classical limit. The effects of this Peierls-like coupling (increased Stokes-shift and additional inhomogeneous broadening) are discussed in the text.

Intermolecular interactions in "dense" systems can be inserted in the model by using the molecular Hamiltonian for each chromophoric entity and adding the interaction term. The form of the Hamiltonian is then the following: ${ }^{[18,54]}$

$$
H=\sum_{i} h_{i}+\frac{1}{2} \sum_{i} \sum_{j \neq i} V_{i j} \hat{\rho}_{i} \hat{\rho}_{j}
$$

where $V_{i j}$ measures the interaction between zwitterionic species at positions $i$ and $j$, and the two summations run over chromophores in the assembly. This Hamiltonian is fairly general: throughout this paper we single out electrostatic forces as the only source of interaction, and choose to assign to each chromophore a fixed length and $+/-e$ charges to the donor/acceptor 
ends for the zwitterionic basis states. Electrostatic interactions are thus inserted as interactions between charges rather than between dipoles: this allows taking into account the length of the chromophores and to describe interactions between spatially close molecules. Since experimental measurements on multichromophoric assemblies were made in solution, the interaction terms $V_{i j}$ are screened by the squared refractive index at optical frequencies ${ }^{[61]}$ $\left(n^{2}=2.1\right.$ for $\left.\mathrm{CHCl}_{3}\right)$. In this paper dimeric and trimeric multichromophores are considered with symmetry $\mathrm{C}_{2 \mathrm{v}}$ and $\mathrm{C}_{3 \mathrm{v}}$, respectively. The length of the chromophore, the interchromophore distance and the angle formed with the main axis of symmetry determine the values of the $V_{i j}$. Also a few predictions on assemblies made up with different chromophores are presented.

The Hamiltonian is written on the basis obtained by the direct product of the $2^{N}$ electronic states $(N=$ number of chromophores) times the vibrational states. The dimension of the problem is $(2 M)^{N}$, where $M$ is the number of vibrational states introduced for each chromophore. ${ }^{[18]}$ Eigenvalues and eigenvectors obtained by diagonalisation are used to calculate spectra of multimers of Series II, obtained with $M=8$ (large enough to get converged results). Calculated spectra of multimers of Series I are not presented since the too large $M$ value needed in this case $(M \geq 18)$ leads to a too big numerical problem.

The values of the first static hyperpolarisability, $\beta$, are obtained through sum-over-states expressions, at the experimental frequency $(2 \omega=1.3 \mathrm{eV})$. In particular, the vector component of the $\boldsymbol{\beta}$ tensor in the direction of the dipole moment $(z)$ is calculated:

$$
\beta_{z}=\frac{1}{3} \sum_{i}\left(\beta_{z i i}+\beta_{i z i}+\beta_{i i z}\right)
$$

where $i$ runs over Cartesian coordinates $(x, y, z)$. If Kleinman symmetry (valid out of resonance) is imposed, ${ }^{[62]}$ this expression reduces to $\beta_{z}=\Sigma_{i} \beta_{z i i}$. Kleinman symmetry is exploited in the presented calculations, after having checked its validity in the relevant regime. The symmetry of the assemblies is also exploited, so that the following expressions are needed:

$$
\begin{array}{ll}
\beta_{z}=\beta_{z z z}+\beta_{z y y} & \text { for } \mathrm{C}_{2 \mathrm{v}}+\text { Kleinman symmetry } \\
\beta_{z}=\beta_{z z z}+2 \beta_{z y y} & \text { for } \mathrm{C}_{3 \mathrm{v}}+\text { Kleinman symmetry }
\end{array}
$$

$M=8$ molecular vibrations per molecular site were used for calculations on both Series. ${ }^{[63]}$ All along this paper the $\beta$ symbol corresponds to the $\beta_{z}$ quantity. Moreover, the $X$ convention, as defined in Ref. ${ }^{[47]}$, is adopted.

\section{Synthesis}

General methods: All air- or water-sensitive reactions were carried out under argon. Solvents were generally dried and distilled prior to use. Reactions were monitored by thin-layer chromatography on Merck silica gel or neutral aluminum oxide $60 \mathrm{~F}_{254}$ precoated aluminum sheets. Column chromatography: Merck silica gel Si 60 (40-63 $\mu \mathrm{m}, 230-400$ mesh), except otherwise noted. Melting points were determined on an Electrothermal IA9300 digital melting point instrument. NMR: Bruker ARX $200\left({ }^{1} \mathrm{H}: 200.13 \mathrm{MHz},{ }^{13} \mathrm{C}: 50.32 \mathrm{MHz}\right)$ or Avance AV $300\left({ }^{1} \mathrm{H}: 300.13 \mathrm{MHz},{ }^{13} \mathrm{C}: 75.48 \mathrm{MHz}\right)$, in $\mathrm{CDCl}_{3}$ solutions; ${ }^{1} \mathrm{H}$ chemical shifts $(\delta)$ are given in ppm relative to TMS as internal standard, $J$ values in $\mathrm{Hz},{ }^{13} \mathrm{C}$ chemical shifts relative to the central peak of $\mathrm{CDCl}_{3}$ at $77.0 \mathrm{ppm}$. High resolution mass spectra measurements were 
performed at the Centre Régional de Mesures Physiques de l'Ouest (C.R.M.P.O., Rennes), using a Micromass MS/MS ZABSpec TOF instrument with EBE TOF geometry; LSIMS (Liquid Secondary Ion Mass Spectrometry) at $8 \mathrm{kV}$ with $\mathrm{Cs}^{+}$in $m$-nitrobenzyl alcohol (mNBA).

${ }^{13} \mathrm{C}$ NMR spectra are available as Supporting Information.

4-[Hexyl(2-hydroxyethyl)amino]benzaldehyde (1) was prepared from hexylaniline, analogously to lit. ${ }^{[64]}$; ${ }^{1} \mathrm{H}$ NMR $\left(200.13 \mathrm{MHz}, \mathrm{CDCl}_{3}\right): \delta=9.69$ (s, $\left.1 \mathrm{H}\right), 7.69$ and 6.72 $\left(\mathrm{AA}^{\prime} \mathrm{XX}, J_{\mathrm{AX}}=9.0 \mathrm{~Hz}, 4 \mathrm{H}\right), 3.85(\mathrm{dt}, J=5.8 \mathrm{~Hz}, 2 \mathrm{H}), 3.59(\mathrm{t}, J=5.8 \mathrm{~Hz}, 2 \mathrm{H}), 3.42(\mathrm{t}, J=$ $7.8 \mathrm{~Hz}, 2 \mathrm{H}), 1.85(\mathrm{t}, J=5.8 \mathrm{~Hz}, 1 \mathrm{H}), 1.62(\mathrm{~m}, 2 \mathrm{H}), 1.37-1.29(\mathrm{~m}, 6 \mathrm{H}), 0.90 \mathrm{ppm}(\mathrm{t}, J=6.5$ $\mathrm{Hz}, 3 \mathrm{H}) ;{ }^{13} \mathrm{C}$ NMR $\left(50.32 \mathrm{MHz}, \mathrm{CDCl}_{3}\right): \delta=190.2,152.9,132.2,124.8,111.0,59.7,52.7$, 51.6, 31.5, 26.7, 26.6, 22.6, 13.9 ppm; HRMS (LSIMS ${ }^{+}$, mNBA): $\mathrm{m} / z$ calcd for $\mathrm{C}_{15} \mathrm{H}_{23} \mathrm{NO}_{2}$ $\left(\mathrm{M}^{+} \cdot\right)$ : 249.1728; found: 249.1724 .

[[4-[Hexyl(2-hydroxyethyl)amino]phenyl]methylene]propanedinitrile (3). A solution of $\mathbf{1}$ $(0.500 \mathrm{~g}, 2.0 \mathrm{mmol})$ and malononitrile $(2)(0.132 \mathrm{~g}, 2.0 \mathrm{mmol})$ in anhydrous ethanol $(40 \mathrm{~mL})$ was refluxed for $18 \mathrm{~h}$. After cooling, the solvent was evaporated under reduced pressure and the crude product was purified by column chromatography $\left(\mathrm{CH}_{2} \mathrm{Cl}_{2} / \mathrm{Et}_{2} \mathrm{O} 95: 5\right)$ to yield 0.490 g (82\%) of 3; m.p. $112-113{ }^{\circ} \mathrm{C}$; ${ }^{1} \mathrm{H}$ NMR $\left(200.13 \mathrm{MHz}, \mathrm{CDCl}_{3}\right): \delta=7.80$ and $6.72\left(\mathrm{AA}^{\prime} \mathrm{XX}\right.$ ', $\left.J_{\mathrm{AX}}=9.3 \mathrm{~Hz}, 4 \mathrm{H}\right), 7.45(\mathrm{~s}, 1 \mathrm{H}), 3.88(\mathrm{dt}, J=5.6 \mathrm{~Hz}, 2 \mathrm{H}), 3.62(\mathrm{t}, J=5.6 \mathrm{~Hz}, 2 \mathrm{H}), 3.46(\mathrm{t}, J=$ $7.8 \mathrm{~Hz}, 2 \mathrm{H}), 1.64(\mathrm{~m}, 2 \mathrm{H}), 1.55(\mathrm{t}, J=5.6 \mathrm{~Hz}, 1 \mathrm{H}), 1.33(\mathrm{~m}, 6 \mathrm{H}), 0.91 \mathrm{ppm}(\mathrm{t}, J=6.4 \mathrm{~Hz}$, $3 \mathrm{H}) ;{ }^{13} \mathrm{C}$ NMR $\left(50.32 \mathrm{MHz}, \mathrm{CDCl}_{3}\right): \delta=157.7,153.1,134.0,119.1,116.0,114.9,111.7$, 71.1, 59.8, 52.6, 51.8, 31.5, 26.8, 26.5, 22.5, 13.9 ppm; HRMS (LSIMS ${ }^{+}$, mNBA): $\mathrm{m} / z$ calcd for $\mathrm{C}_{18} \mathrm{H}_{23} \mathrm{~N}_{3} \mathrm{O}\left(\mathrm{M}^{+} \cdot\right)$ : 297.1841; found: 297.1840 .

4-[Hexyl[2-[(tetrahydro-2H-pyran-2-yl)oxy]ethyl]amino]benzaldehyde (4). To a solution of $\mathbf{3}$ $(2.85 \mathrm{~g}, 11.4 \mathrm{mmol})$ and 3,4-dihydro-2H-pyran (DHP, $2.10 \mathrm{~mL}, 23.0 \mathrm{mmol}$ ) in anhydrous $\mathrm{CH}_{2} \mathrm{Cl}_{2}(56 \mathrm{~mL})$, was added pyridinium $p$-toluenesulfonate (PPTS, $0.579 \mathrm{~g}, 2.3 \mathrm{mmol}$ ). The mixture was stirred at $20{ }^{\circ} \mathrm{C}$ for $15 \mathrm{~h}$. Water was added, the organic layer was separated and dried $\left(\mathrm{Na}_{2} \mathrm{SO}_{4}\right)$. After evaporation of the solvent, the crude product was purified by column chromatography $\left(\mathrm{CH}_{2} \mathrm{Cl}_{2} / \mathrm{AcOEt}\right.$, gradient from 100:0 to 90:10) to yield $3.78 \mathrm{~g}(99 \%)$ of $\mathbf{4} ;{ }^{1} \mathrm{H}$ NMR $\left(200.13 \mathrm{MHz}, \mathrm{CDCl}_{3}\right): \delta=9.71(\mathrm{~s}, 1 \mathrm{H}), 7.70$ and $6.71\left(\mathrm{AA}^{\prime} \mathrm{XX}{ }^{\prime}, J_{\mathrm{AX}}=9.1 \mathrm{~Hz}, 4 \mathrm{H}\right)$, $4.58(\mathrm{~m}, 1 \mathrm{H}), 3.94-3.36(\mathrm{~m}, 8 \mathrm{H}), 1.82-1.42(\mathrm{~m}, 8 \mathrm{H}), 1.33(\mathrm{~m}, 6 \mathrm{H}), 0.90 \mathrm{ppm}(\mathrm{t}, J=6.6 \mathrm{~Hz}$, $3 \mathrm{H}) ;{ }^{13} \mathrm{C} \mathrm{NMR}\left(50.32 \mathrm{MHz}, \mathrm{CDCl}_{3}\right): \delta=189.8,152.6,132.0,124.8,110.8,99.0,64.5,62.1$, 51.4, 50.5, 31.5, 30.4, 26.7, 26.5, 25.2, 22.5, 19.3, 13.9 ppm; HRMS (LSIMS $\left.{ }^{+}, \mathrm{mNBA}^{2}\right): \mathrm{m} / \mathrm{z}$ calcd for $\mathrm{C}_{20} \mathrm{H}_{31} \mathrm{NO}_{3}\left(\mathrm{M}^{+} \cdot\right)$ : 333.2304; found: 333.2306.

$\mathrm{N}$-Hexyl-4-[(1E)-2-(4-nitrophenyl)ethenyl]-N-[2-[(tetrahydro-2H-pyran-2-yl)oxy]ethyl]benzenamine (6a). To a solution of 4 (0.981 g, $2.94 \mathrm{mmol})$ and diethyl (4nitrobenzyl)phosphonate (5) $(0.885 \mathrm{~g}, 3.24 \mathrm{mmol})$ in dry THF $(25 \mathrm{~mL})$, was added $\mathrm{NaH}$ (0.188 g, 60\% dispersion in mineral oil). The mixture was stirred at $20{ }^{\circ} \mathrm{C}$ for $16 \mathrm{~h}$. After addition of water $(50 \mathrm{~mL})$, the organic layer was separated and dried $\left(\mathrm{Na}_{2} \mathrm{SO}_{4}\right)$. After evaporation of the solvent, the crude product was purified by column chromatography $\left(\mathrm{CH}_{2} \mathrm{Cl}_{2}\right)$ to yield $0.794 \mathrm{~g}(60 \%)$ of $\mathbf{6 a} ;{ }^{1} \mathrm{H}$ NMR $\left(200.13 \mathrm{MHz}, \mathrm{CDCl}_{3}\right): \delta=8.17$ and 7.55 $\left(\mathrm{AA}^{\prime} \mathrm{XX} X^{\prime}, J_{\mathrm{AX}}=8.8 \mathrm{~Hz}, 4 \mathrm{H}\right), 7.41$ and $6.69\left(\mathrm{AA}^{\prime} \mathrm{XX} X^{\prime}, J_{\mathrm{AX}}=8.8 \mathrm{~Hz}, 4 \mathrm{H}\right), 7.19(\mathrm{~d}, J=16.2$ $\mathrm{Hz}, 1 \mathrm{H}), 6.89(\mathrm{~d}, J=16.2 \mathrm{~Hz}, 1 \mathrm{H}), 4.60(\mathrm{~m}, 1 \mathrm{H}), 3.95-3.78(\mathrm{~m}, 2 \mathrm{H}), 3.66-3.43(\mathrm{~m}, 4 \mathrm{H}), 3.37$ $(\mathrm{t}, J=7.7 \mathrm{~Hz}, 2 \mathrm{H}), 1.88-1.48(\mathrm{~m}, 8 \mathrm{H}), 1.38-1.28(\mathrm{~m}, 6 \mathrm{H}), 0.90 \mathrm{ppm}(\mathrm{t}, J=6.5 \mathrm{~Hz}, 3 \mathrm{H}) ;{ }^{13} \mathrm{C}$ NMR (50.32 MHz, $\left.\mathrm{CDCl}_{3}\right): \delta=148.6,145.6,145.0,133.6,128.5,125.9,124.1,123.5,121.0$, 111.6, 99.1, 64.8, 62.2, 51.4, 50.5, 31.6, 30.6, 27.0, 26.7, 25.3, 22.6, 19.4, 14.0 ppm; HRMS (LSIMS ${ }^{+}, \mathrm{mNBA}$ ): $\mathrm{m} / z$ calcd for $\mathrm{C}_{27} \mathrm{H}_{36} \mathrm{~N}_{2} \mathrm{O}_{4}\left(\mathrm{M}^{+} \cdot\right)$ : 452.2675 ; found: 452.2662 . 
2-[Hexyl[4-[(1E)-2-(4-nitrophenyl)ethenyl]phenyl]amino]ethanol $(\boldsymbol{6} \boldsymbol{b})$. To a solution of $\mathbf{6 a}$ (0.710 g, $1.57 \mathrm{mmol})$ in $12 \mathrm{~mL}$ of $\mathrm{CH}_{2} \mathrm{Cl}_{2} / \mathrm{EtOH}(1: 1)$, was added $1 \mathrm{M} \mathrm{HCl}(0.8 \mathrm{~mL})$. The mixture was refluxed for $17 \mathrm{~h}$. After cooling, water $(24 \mathrm{~mL})$ was added, the mixture was made slightly basic with aqueous $\mathrm{NaHCO}_{3}$ and extracted with $\mathrm{CH}_{2} \mathrm{Cl}_{2}$. The combined organic layers were dried $\left(\mathrm{Na}_{2} \mathrm{SO}_{4}\right)$ and after evaporation of the solvent, the crude product was purified by column chromatography $\left(\mathrm{CH}_{2} \mathrm{Cl}_{2} / \mathrm{AcOEt}\right.$, gradient from 100:0 to 97:3) to yield $0.569 \mathrm{~g}(98 \%)$ of 6b; m.p. $111-112{ }^{\circ} \mathrm{C} ;{ }^{1} \mathrm{H}$ NMR $\left(200.13 \mathrm{MHz}, \mathrm{CDCl}_{3}\right): \delta=8.17$ and $7.55\left(\mathrm{AA}^{\prime} \mathrm{XX}{ }^{\prime}, J_{\mathrm{AX}}=\right.$ $8.8 \mathrm{~Hz}, 4 \mathrm{H}), 7.41$ and $6.72\left(\mathrm{AA}^{\prime} \mathrm{XX} X^{\prime}, J_{\mathrm{AX}}=9.0 \mathrm{~Hz}, 4 \mathrm{H}\right), 7.19(\mathrm{~d}, J=16.3 \mathrm{~Hz}, 1 \mathrm{H}), 6.90(\mathrm{~d}, J$ $=16.3 \mathrm{~Hz}, 1 \mathrm{H}), 3.83(\mathrm{dt}, J=5.9 \mathrm{~Hz}, 2 \mathrm{H}), 3.54(\mathrm{t}, J=5.9 \mathrm{~Hz}, 2 \mathrm{H}), 3.37(\mathrm{t}, J=7.7 \mathrm{~Hz}, 2 \mathrm{H})$, $1.64(\mathrm{t}, J=5.9 \mathrm{~Hz}, 1 \mathrm{H}), 1.61(\mathrm{~m}, 2 \mathrm{H}), 1.32(\mathrm{~m}, 6 \mathrm{H}), 0.90 \mathrm{ppm}(\mathrm{t}, J=6.6 \mathrm{~Hz}, 3 \mathrm{H}) ;{ }^{13} \mathrm{C} \mathrm{NMR}$ $\left(50.32 \mathrm{MHz}, \mathrm{CDCl}_{3}\right): \delta=148.8,145.8,144.9,133.4,128.5,126.0,124.2,124.1,121.5,112.2$, 60.1, 52.9, 51.6, 31.6, 26.8, 26.7, 22.6, 14.0 ppm; HRMS (LSIMS $\left.{ }^{+}, \mathrm{mNBA}\right): \mathrm{m} / \mathrm{z}$ calcd for $\mathrm{C}_{22} \mathrm{H}_{28} \mathrm{~N}_{2} \mathrm{O}_{3}\left(\mathrm{M}^{+} \cdot\right)$ : 368.2100; found: 368.2100 .

Benzoic acid, 2-[hexyl[4-[(1E)-2-(4-nitrophenyl)ethenyl]phenyl]amino]ethyl ester (I-1). To a solution of $\mathbf{6 b}(60 \mathrm{mg}, 0.163 \mathrm{mmol})$ in dry $\mathrm{CH}_{2} \mathrm{Cl}_{2}(0.75 \mathrm{~mL}$, stabilized with amylene $)$ under argon, were added $\mathrm{Et}_{3} \mathrm{~N}(57 \mu \mathrm{L})$ and benzoyl chloride (7) $(28 \mu \mathrm{L}, 0.241 \mathrm{mmol})$. The mixture was stirred at $20^{\circ} \mathrm{C}$ for $4 \mathrm{~h}$ and then refluxed for $1 \mathrm{~h}$. Water was added and the mixture was extracted with $\mathrm{CH}_{2} \mathrm{Cl}_{2}$. The extracts were dried $\left(\mathrm{Na}_{2} \mathrm{SO}_{4}\right)$ and after evaporation of the solvent, the crude product was purified by column chromatography $\left(\mathrm{CH}_{2} \mathrm{Cl}_{2}\right)$ to yield $69.5 \mathrm{mg}(90 \%)$ of I-1; ${ }^{1} \mathrm{H}$ NMR $\left(200.13 \mathrm{MHz}, \mathrm{CDCl}_{3}\right): \delta=8.17$ and $7.55\left(\mathrm{AA}^{\prime} \mathrm{XX}, J_{\mathrm{AX}}=9.0 \mathrm{~Hz}, 4 \mathrm{H}\right), 8.05-$ $8.00(\mathrm{~m}, 2 \mathrm{H}), 7.62-7.53(\mathrm{~m}, 1 \mathrm{H}), 7.49-7.40(\mathrm{~m}, 2 \mathrm{H}), 7.44$ and $6.77\left(\mathrm{AA}^{\prime} \mathrm{XX}{ }^{\prime}, J_{\mathrm{AX}}=8.9 \mathrm{~Hz}\right.$, $4 \mathrm{H}), 7.20(\mathrm{~d}, J=16.2 \mathrm{~Hz}, 1 \mathrm{H}), 6.91(\mathrm{~d}, J=16.2 \mathrm{~Hz}, 1 \mathrm{H}), 4.50(\mathrm{t}, J=6.3 \mathrm{~Hz}, 2 \mathrm{H}), 3.76(\mathrm{t}, J=$ $6.3 \mathrm{~Hz}, 2 \mathrm{H}), 3.41(\mathrm{t}, J=7.7 \mathrm{~Hz}, 2 \mathrm{H}), 1.65(\mathrm{~m}, 2 \mathrm{H}), 1.35-1.30(\mathrm{~m}, 6 \mathrm{H}), 0.90 \mathrm{ppm}(\mathrm{t}, J=6.4$ $\mathrm{Hz}, 3 \mathrm{H}) ;{ }^{13} \mathrm{C}$ NMR $\left(50.32 \mathrm{MHz}, \mathrm{CDCl}_{3}\right): \delta=166.5,148.3,145.8,144.9,133.5,133.1,129.8$, 129.6, 128.6, 128.4, 126.0, 124.2, 124.1, 121.5, 111.9, 61.9, 51.4, 49.3, 31.6, 27.2, 26.7, 22.6, 14.0 ppm; HRMS (LSIMS ${ }^{+}$, mNBA): $\mathrm{m} / z$ calcd for $\mathrm{C}_{29} \mathrm{H}_{32} \mathrm{~N}_{2} \mathrm{O}_{4}\left(\mathrm{M}^{+} \cdot\right.$ ): 472.2362; found: 472.2359 .

1,2-Benzenedicarboxylic acid, bis[2-[hexyl[4-[(1E)-2-(4-nitrophenyl)ethenyl]phenyl]amino]ethyl] ester (I-2O). To a solution of phthaloyl chloride (8a) $(16.7 \mathrm{mg}, 82.3 \mu \mathrm{mol})$ in dry $\mathrm{CH}_{2} \mathrm{Cl}_{2}\left(1.0 \mathrm{~mL}\right.$, stabilized with amylene) under argon, were added $\mathrm{Et}_{3} \mathrm{~N}(51 \mu \mathrm{L})$ and $\mathbf{6 b}(80$ $\mathrm{mg}, 217 \mu \mathrm{mol})$. The mixture was stirred at $20^{\circ} \mathrm{C}$ for $4 \mathrm{~h}$ and then refluxed for $1 \mathrm{~h}$. Water was added and the mixture was extracted with $\mathrm{CH}_{2} \mathrm{Cl}_{2}$. The extracts were dried $\left(\mathrm{Na}_{2} \mathrm{SO}_{4}\right)$ and after evaporation of the solvent, the crude product was purified by column chromatography $\left(\mathrm{CH}_{2} \mathrm{Cl}_{2}\right.$ then $\left.\mathrm{CH}_{2} \mathrm{Cl}_{2} / \mathrm{AcOEt} 95: 5\right)$ to yield $60.4 \mathrm{mg}(85 \%)$ of $\mathbf{I - 2 O} ;{ }^{1} \mathrm{H}$ NMR $(200.13 \mathrm{MHz}$, $\left.\mathrm{CDCl}_{3}\right): \delta=8.16$ and $7.52\left(\mathrm{AA}^{\prime} \mathrm{XX} X^{\prime}, J_{\mathrm{AX}}=8.9 \mathrm{~Hz}, 8 \mathrm{H}\right.$ ), 7.68 and 7.55 (AA'XX', 4H), 7.39 and $6.71\left(\mathrm{AA}^{\prime} \mathrm{XX}, J_{\mathrm{AX}}=8.8 \mathrm{~Hz}, 8 \mathrm{H}\right), 7.15(\mathrm{~d}, J=16.3 \mathrm{~Hz}, 2 \mathrm{H}), 6.86(\mathrm{~d}, J=16.3 \mathrm{~Hz}, 2 \mathrm{H})$, $4.43(\mathrm{t}, J=6.4 \mathrm{~Hz}, 4 \mathrm{H}), 3.70(\mathrm{t}, J=6.4 \mathrm{~Hz}, 4 \mathrm{H}), 3.34(\mathrm{t}, J=7.6 \mathrm{~Hz}, 4 \mathrm{H}), 1.59(\mathrm{~m}, 4 \mathrm{H}), 1.31-$ $1.24(\mathrm{~m}, 12 \mathrm{H}), 0.87 \mathrm{ppm}(\mathrm{t}, J=6.6 \mathrm{~Hz}, 6 \mathrm{H}) ;{ }^{13} \mathrm{C} \mathrm{NMR}\left(75.48 \mathrm{MHz}, \mathrm{CDCl}_{3}\right): \delta=167.4$, $148.2,145.8,144.8,133.4,131.7,131.3,128.9,128.6,126.0,124.2,124.1,121.5,111.8,62.4$, 51.4, 49.0, 31.6, 27.1, 26.6, 22.6, 14.0 ppm; HRMS (LSIMS $\left.{ }^{+}, \mathrm{mNBA}\right): \mathrm{m} / z$ calcd for $\mathrm{C}_{52} \mathrm{H}_{58} \mathrm{~N}_{4} \mathrm{O}_{8}\left(\mathrm{M}^{+} \cdot\right)$ : 866.4255; found: 866.4261.

1,3-Benzenedicarboxylic acid, bis[2-[hexyl[4-[(1E)-2-(4-nitrophenyl)ethenyl]phenyl]amino]ethyl] ester (I-2M). Reaction of isophthaloyl chloride $(\mathbf{8 b})(7.6 \mathrm{mg}, 37.4 \mu \mathrm{mol})$ with $\mathbf{6 b}(40$ $\mathrm{mg}, 108.6 \mu \mathrm{mol})$, as described for I-2O, afforded $30.7 \mathrm{mg}(95 \%)$ of $\mathbf{I - 2 M} ;{ }^{1} \mathrm{H}$ NMR $(200.13$ $\left.\mathrm{MHz}, \mathrm{CDCl}_{3}\right): \delta=8.67(\mathrm{t}, J=1.7 \mathrm{~Hz}, 1 \mathrm{H}), 8.20(\mathrm{dd}, J=7.5 \mathrm{~Hz}, 1.7 \mathrm{~Hz}, 2 \mathrm{H}), 8.17$ and 7.54 $\left(\mathrm{AA}^{\prime} \mathrm{XX}, J_{\mathrm{AX}}=8.9 \mathrm{~Hz}, 8 \mathrm{H}\right), 7.53(\mathrm{t}, J=7.5 \mathrm{~Hz}, 1 \mathrm{H}), 7.44$ and $6.76\left(\mathrm{AA}^{\prime} \mathrm{XX}^{\prime}, J_{\mathrm{AX}}=8.8 \mathrm{~Hz}\right.$, $8 \mathrm{H}), 7.19(\mathrm{~d}, J=16.2 \mathrm{~Hz}, 2 \mathrm{H}), 6.90(\mathrm{~d}, J=16.2 \mathrm{~Hz}, 2 \mathrm{H}), 4.52(\mathrm{t}, J=6.4 \mathrm{~Hz}, 4 \mathrm{H}), 3.76(\mathrm{t}, J=$ $6.4 \mathrm{~Hz}, 4 \mathrm{H}), 3.40(\mathrm{t}, J=7.6 \mathrm{~Hz}, 4 \mathrm{H}), 1.63(\mathrm{~m}, 4 \mathrm{H}), 1.35-1.27(\mathrm{~m}, 12 \mathrm{H}), 0.89 \mathrm{ppm}(\mathrm{t}, J=6.3$ 
$\mathrm{Hz}, 6 \mathrm{H}) ;{ }^{13} \mathrm{C} \mathrm{NMR}\left(50.32 \mathrm{MHz}, \mathrm{CDCl}_{3}\right): \delta=165.6,148.3,145.9,144.9,134.0,133.4,130.8$, 130.4, 128.7, 128.6, 126.0, 124.3, 124.1, 121.6, 111.9, 62.3, 51.4, 49.2, 31.7, 27.2, 26.7, 22.6, 14.0 ppm; HRMS (LSIMS ${ }^{+}$, mNBA): $\mathrm{m} / z$ calcd for $\mathrm{C}_{52} \mathrm{H}_{58} \mathrm{~N}_{4} \mathrm{O}_{8}\left(\mathrm{M}^{+} \cdot\right.$ ): 866.4255; found: 866.4245 .

1,4-Benzenedicarboxylic acid, bis[2-[hexyl[4-[(1E)-2-(4-nitrophenyl)ethenyl]phenyl]amino]ethyl] ester $(\mathbf{I}-\mathbf{2 P})$. Reaction of terephthaloyl chloride $(\mathbf{8 c})(14.4 \mathrm{mg}, 70.9 \mu \mathrm{mol})$ with $\mathbf{6 b}(80$ $\mathrm{mg}, 217 \mu \mathrm{mol})$, as described for I-2O, afforded $56.9 \mathrm{mg}(93 \%)$ of $\mathbf{I - 2 P} ;{ }^{1} \mathrm{H}$ NMR (200.13 $\left.\mathrm{MHz}, \mathrm{CDCl}_{3}\right): \delta=8.18$ and $7.56\left(\mathrm{AA}^{\prime} \mathrm{XX}, J_{\mathrm{AX}}=8.9 \mathrm{~Hz}, 8 \mathrm{H}\right), 8.06(\mathrm{~s}, 4 \mathrm{H}), 7.43$ and 6.75 $\left(\mathrm{AA}^{\prime} \mathrm{XX}^{\prime}, J_{\mathrm{AX}}=8.9 \mathrm{~Hz}, 8 \mathrm{H}\right), 7.20(\mathrm{~d}, J=16.3 \mathrm{~Hz}, 2 \mathrm{H}), 6.91(\mathrm{~d}, J=16.3 \mathrm{~Hz}, 2 \mathrm{H}), 4.51(\mathrm{t}, J=$ $6.1 \mathrm{~Hz}, 4 \mathrm{H}), 3.76(\mathrm{t}, J=6.1 \mathrm{~Hz}, 4 \mathrm{H}), 3.39(\mathrm{t}, J=7.6 \mathrm{~Hz}, 4 \mathrm{H}), 1.63(\mathrm{~m}, 4 \mathrm{H}), 1.35-1.25(\mathrm{~m}$, $12 \mathrm{H}), 0.89 \mathrm{ppm}(\mathrm{t}, J=6.4 \mathrm{~Hz}, 6 \mathrm{H}) ;{ }^{13} \mathrm{C} \mathrm{NMR}\left(50.32 \mathrm{MHz}, \mathrm{CDCl}_{3}\right): \delta=165.6,148.3,145.8$, 144.9, 133.7, 133.4, 129.6, 128.6, 126.0, 124.3, 124.1, 121.6, 111.9, 62.4, 51.3, 49.2, 31.6, 27.1, 26.7, 22.6, 14.0 ppm; HRMS (LSIMS ${ }^{+}$, mNBA): $m / z$ calcd for $\mathrm{C}_{52} \mathrm{H}_{58} \mathrm{~N}_{4} \mathrm{O}_{8}\left(\mathrm{M}^{+} \cdot\right)$ : 866.4255; found: 866.4264 .

1,3,5-Benzenetricarboxylic acid, tris[2-[hexyl[4-[(1E)-2-(4-nitrophenyl)ethenyl]phenyl]amino]ethyl] ester (I-3). Reaction of 1,3,5-benzenetricarbonyl chloride (9) (9.9 mg, 37.3 $\mu \mathrm{mol})$ with $\mathbf{6 b}(62 \mathrm{mg}, 168.3 \mu \mathrm{mol})$, as described for I-2O, afforded $39.0 \mathrm{mg}(83 \%)$ of $\mathbf{I - 3} ;{ }^{1} \mathrm{H}$ NMR (200.13 MHz, $\left.\mathrm{CDCl}_{3}\right): \delta=8.81(\mathrm{~s}, 3 \mathrm{H}), 8.15$ and $7.52\left(\mathrm{AA}^{\prime} \mathrm{XX} X^{\prime}, J_{\mathrm{AX}}=8.8 \mathrm{~Hz}, 12 \mathrm{H}\right)$, 7.43 and $6.76\left(\mathrm{AA}^{\prime} \mathrm{XX}, J_{\mathrm{AX}}=8.9 \mathrm{~Hz}, 12 \mathrm{H}\right), 7.16(\mathrm{~d}, J=16.3 \mathrm{~Hz}, 3 \mathrm{H}), 6.88(\mathrm{~d}, J=16.3 \mathrm{~Hz}$, $3 \mathrm{H}), 4.54(\mathrm{t}, J=6.2 \mathrm{~Hz}, 6 \mathrm{H}), 3.76(\mathrm{t}, J=6.2 \mathrm{~Hz}, 6 \mathrm{H}), 3.39(\mathrm{t}, J=7.4 \mathrm{~Hz}, 6 \mathrm{H}), 1.62(\mathrm{~m}, 6 \mathrm{H})$, $1.35-1.27(\mathrm{~m}, 18 \mathrm{H}), 0.89 \mathrm{ppm}(\mathrm{t}, J=6.4 \mathrm{~Hz}, 9 \mathrm{H}) ;{ }^{13} \mathrm{C}$ NMR $\left(50.32 \mathrm{MHz}, \mathrm{CDCl}_{3}\right): \delta=164.7$, 148.2, 145.8, 144.8, 134.7, 133.3, 131.0, 128.6, 126.0, 124.4, 124.1, 121.6, 111.9, 62.6, 51.3, 49.0, 31.6, 27.1, 26.7, 22.6, 14.0 ppm; HRMS (LSIMS ${ }^{+}, \mathrm{mNBA}$ ): $\mathrm{m} / z$ calcd for $\mathrm{C}_{75} \mathrm{H}_{84} \mathrm{~N}_{6} \mathrm{O}_{12}$ $\left(\mathrm{M}^{+} \cdot\right)$ : 1260.6147; found: 1260.6142 .

[[4-[[2-(Benzoyloxy)ethyl]hexylamino]phenyl]methylene]propanedinitrile (II-1). Reaction of 3 (57 mg, $0.192 \mathrm{mmol}$ ) with benzoyl chloride (7) (54 mg, $0.384 \mathrm{mmol})$, as described for I-1, with subsequent purification by column chromatography (heptane $/ \mathrm{CH}_{2} \mathrm{Cl}_{2} 60: 40$ then 40:60), afforded $75.6 \mathrm{mg}(98 \%)$ of II-1; m.p. $72-73{ }^{\circ} \mathrm{C} ;{ }^{1} \mathrm{H}$ NMR $\left(200.13 \mathrm{MHz}, \mathrm{CDCl}_{3}\right): \delta=7.99(\mathrm{~m}$, $2 \mathrm{H}), 7.82$ and $6.79\left(\mathrm{AA}^{\prime} \mathrm{XX} X^{\prime}, J_{\mathrm{AX}}=9.4 \mathrm{~Hz}, 4 \mathrm{H}\right), 7.63-7.55(\mathrm{~m}, 1 \mathrm{H}), 7.46(\mathrm{~s}, 1 \mathrm{H}), 7.48-7.41$ $(\mathrm{m}, 2 \mathrm{H}), 4.52(\mathrm{t}, J=6.3 \mathrm{~Hz}, 2 \mathrm{H}), 3.83(\mathrm{t}, J=6.3 \mathrm{~Hz}, 2 \mathrm{H}), 3.48(\mathrm{t}, J=7.7 \mathrm{~Hz}, 2 \mathrm{H}), 1.66(\mathrm{~m}$, $2 \mathrm{H}), 1.36-1.29(\mathrm{~m}, 6 \mathrm{H}), 0.90 \mathrm{ppm}(\mathrm{m}, 3 \mathrm{H}) ;{ }^{13} \mathrm{C} \mathrm{NMR}\left(50.32 \mathrm{MHz}, \mathrm{CDCl}_{3}\right): \delta=166.2,157.8$, 152.6, 133.8, 133.2, 129.5, 129.3, 128.4, 119.4, 115.8, 114.7, 111.7, 72.0, 61.3, 51.4, 49.1, 31.4, 26.9, 26.4, 22.4, 13.9; HRMS (LSIMS ${ }^{+}, \mathrm{mNBA}$ ): $\mathrm{m} / z$ calcd for $\mathrm{C}_{25} \mathrm{H}_{27} \mathrm{~N}_{3} \mathrm{O}_{2}\left(\mathrm{M}^{+} \cdot\right.$ ): 401.2103; found: 401.2093 .

1,2-Benzenedicarboxylic acid, bis[2-[[4-(2,2-dicyanoethenyl)phenyl]hexylamino]ethyl] ester (II-2O). Reaction of phthaloyl chloride (8a) $(13.0 \mathrm{mg}, 64 \mu \mathrm{mol})$ with 3 (58 mg, $195 \mu \mathrm{mol})$, as described for I-2O, with subsequent purification by column chromatography (heptane $/ \mathrm{CH}_{2} \mathrm{Cl}_{2}$ 30:70), afforded $37.9 \mathrm{mg}$ (82\%) of II-2O; m.p. 76-77 ${ }^{\circ} \mathrm{C} ;{ }^{1} \mathrm{H}$ NMR $\left(200.13 \mathrm{MHz}, \mathrm{CDCl}_{3}\right): \delta=$ 7.78 and $6.75\left(\mathrm{AA}^{\prime} \mathrm{XX}, J_{\mathrm{AX}}=9.1 \mathrm{~Hz}, 8 \mathrm{H}\right), 7.67-7.53\left(\mathrm{AA}^{\prime} \mathrm{XX}, 4 \mathrm{H}\right), 7.44(\mathrm{~s}, 2 \mathrm{H}), 4.46(\mathrm{t}, J$ $=6.2 \mathrm{~Hz}, 4 \mathrm{H}), 3.79(\mathrm{t}, J=6.2 \mathrm{~Hz}, 4 \mathrm{H}), 3.43(\mathrm{t}, J=7.8 \mathrm{~Hz}, 4 \mathrm{H}), 1.62(\mathrm{~m}, 4 \mathrm{H}), 1.35-1.25(\mathrm{~m}$, $12 \mathrm{H}), 0.89 \mathrm{ppm}(\mathrm{t}, J=6.2 \mathrm{~Hz}, 6 \mathrm{H}) ;{ }^{13} \mathrm{C} \mathrm{NMR}\left(50.32 \mathrm{MHz}, \mathrm{CDCl}_{3}\right): \delta=167.2,157.8$, 152.5,133.9, 131.5, 131.4, 128.9, 119.6, 115.7, 114.7, 111.8, 72.7, 62.0, 51.5, 49.0, 31.5, 27.0, 26.5, 22.6, 14.0; HRMS (LSIMS ${ }^{+}$, mNBA): $\mathrm{m} / z$ calcd for $\mathrm{C}_{44} \mathrm{H}_{48} \mathrm{~N}_{6} \mathrm{O}_{4}\left(\mathrm{M}^{+} \cdot\right.$ ): 724.3737 ; found: 724.3728 .

1,3-Benzenedicarboxylic acid, bis[2-[[4-(2,2-dicyanoethenyl)phenyl]hexylamino]ethyl] ester (II-2M). Reaction of isophthaloyl chloride (8b) $(13.0 \mathrm{mg}, 64 \mu \mathrm{mol})$ with $3(58 \mathrm{mg}, 195$ $\mu \mathrm{mol})$, as described for $\mathbf{I - 2 O}$, with subsequent purification by column chromatography 
(heptane/ $\mathrm{CH}_{2} \mathrm{Cl}_{2}$ 30:70), afforded $43.2 \mathrm{mg}$ (93\%) of II-2M; m.p. 115-116 ${ }^{\circ} \mathrm{C} ;{ }^{1} \mathrm{H}$ NMR $\left(200.13 \mathrm{MHz}, \mathrm{CDCl}_{3}\right): \delta=8.57(\mathrm{~s}, 1 \mathrm{H}), 8.15(\mathrm{~d}, J=7.8 \mathrm{~Hz}, 2 \mathrm{H}), 7.80$ and 6.79 (AA'XX', $\left.J_{\mathrm{AX}}=9.1 \mathrm{~Hz}, 8 \mathrm{H}\right), 7.51(\mathrm{t}, J=7.8 \mathrm{~Hz}, 1 \mathrm{H}), 7.44(\mathrm{~s}, 2 \mathrm{H}), 4.53(\mathrm{t}, J=6.1 \mathrm{~Hz}, 4 \mathrm{H}), 3.83(\mathrm{t}, J=$ $6.1 \mathrm{~Hz}, 4 \mathrm{H}), 3.45(\mathrm{t}, J=7.9 \mathrm{~Hz}, 4 \mathrm{H}), 1.65(\mathrm{~m}, 4 \mathrm{H}), 1.31(\mathrm{~m}, 12 \mathrm{H}), 0.88 \mathrm{ppm}(\mathrm{t}, J=6.7 \mathrm{~Hz}$, $6 \mathrm{H}) ;{ }^{13} \mathrm{C}$ NMR $\left(50.32 \mathrm{MHz}, \mathrm{CDCl}_{3}\right): \delta=165.3,157.8,152.7,134.0,133.9,130.8,130.0$, $128.8,119.5,115.7,114.7,111.8,72.3,61.8,51.4,49.0,31.4,27.0,26.5,22.5,13.9$; HRMS (LSIMS ${ }^{+}$, mNBA): $m / z$ calcd for $\mathrm{C}_{44} \mathrm{H}_{48} \mathrm{~N}_{6} \mathrm{O}_{4}\left(\mathrm{M}^{+} \cdot\right.$ ): 724.3737 ; found: 724.3738 .

1,4-Benzenedicarboxylic acid, bis[2-[[4-(2,2-dicyanoethenyl)phenyl]hexylamino]ethyl] ester (II-2P). Reaction of terephthaloyl chloride (8c) $(13.0 \mathrm{mg}, 64 \mu \mathrm{mol})$ with 3 (58 mg, 195 $\mu \mathrm{mol})$, as described for $\mathbf{I - 2 O}$, with subsequent purification by column chromatography (heptane/ $\mathrm{CH}_{2} \mathrm{Cl}_{2} 30: 70$ ), afforded $41.1 \mathrm{mg}$ (89\%) of II-2P; m.p. 155-156 ${ }^{\circ} \mathrm{C} ;{ }^{1} \mathrm{H}$ NMR $\left(200.13 \mathrm{MHz}, \mathrm{CDCl}_{3}\right): \delta=8.02(\mathrm{~s}, 4 \mathrm{H}), 7.80$ and $6.80\left(\mathrm{AA}^{\prime} \mathrm{XX}^{\prime}, J_{\mathrm{AX}}=8.9 \mathrm{~Hz}, 8 \mathrm{H}\right), 7.45(\mathrm{~s}$, $2 \mathrm{H}), 4.55(\mathrm{t}, J=5.9 \mathrm{~Hz}, 4 \mathrm{H}), 3.85(\mathrm{t}, J=5.9 \mathrm{~Hz}, 4 \mathrm{H}), 3.47(\mathrm{t}, J=7.5 \mathrm{~Hz}, 4 \mathrm{H}), 1.66(\mathrm{~m}, 4 \mathrm{H})$, $1.33(\mathrm{~m}, 12 \mathrm{H}), 0.90 \mathrm{ppm}(\mathrm{m}, 6 \mathrm{H}) ;{ }^{13} \mathrm{C}$ NMR $\left(50.32 \mathrm{MHz}, \mathrm{CDCl}_{3}\right): \delta=165.4,157.8,152.7$, 133.9, 133.5, 129.6, 119.6, 115.7, 114.7, 111.9, 72.6, 61.9, 51.4, 49.1, 31.5, 27.0, 26.5, 22.5, 13.9; HRMS (LSIMS ${ }^{+}$, mNBA): $m / z$ calcd for $\mathrm{C}_{44} \mathrm{H}_{48} \mathrm{~N}_{6} \mathrm{O}_{4}\left(\mathrm{M}^{+} \cdot\right.$ ): 724.3737 ; found: 724.3732 .

1,3,5-Benzenetricarboxylic acid, tris[2-[[4-(2,2-dicyanoethenyl)phenyl]hexylamino]ethyl] ester (II-3). Reaction of 1,3,5-benzenetricarbonyl chloride (9) (17.0 mg, $64 \mu \mathrm{mol})$ with 3 (87.9 $\mathrm{mg}, 296 \mu \mathrm{mol}$ ), as described for I-20, with subsequent purification by column chromatography (heptane/ $\mathrm{CH}_{2} \mathrm{Cl}_{2} 30: 70$ ), afforded $23.4 \mathrm{mg}(35 \%)$ of II-3; m.p. 156-157 ${ }^{\circ} \mathrm{C}$; ${ }^{1} \mathrm{H}$ NMR $\left(200.13 \mathrm{MHz}, \mathrm{CDCl}_{3}\right): \delta=8.69(\mathrm{~s}, 3 \mathrm{H}), 7.80$ and $6.81\left(\mathrm{AA}^{\prime} \mathrm{XX}{ }^{\prime}, J_{\mathrm{AX}}=9.2 \mathrm{~Hz}\right.$, $12 \mathrm{H}), 7.44(\mathrm{~s}, 3 \mathrm{H}), 4.58(\mathrm{t}, J=5.9 \mathrm{~Hz}, 6 \mathrm{H}), 3.87(\mathrm{t}, J=5.9 \mathrm{~Hz}, 6 \mathrm{H}), 3.47(\mathrm{t}, J=7.8 \mathrm{~Hz}, 6 \mathrm{H})$, $1.67(\mathrm{~m}, 6 \mathrm{H}), 1.34(\mathrm{~m}, 18 \mathrm{H}), 0.90 \mathrm{ppm}(\mathrm{t}, J=6.5 \mathrm{~Hz}, 9 \mathrm{H}) ;{ }^{13} \mathrm{C} \mathrm{NMR}\left(50.32 \mathrm{MHz}, \mathrm{CDCl}_{3}\right): \delta$ $=164.4,157.9,152.8,134.8,134.0,130.7,119.7,115.8,114.7,111.8,72.5,62.3,51.2,48.9$, 31.5, 27.0, 26.6, 22.6, 14.0; HRMS (LSIMS $\left.{ }^{+}, \mathrm{mNBA}\right): \mathrm{m} / \mathrm{z}$ calcd for $\mathrm{C}_{63} \mathrm{H}_{70} \mathrm{~N}_{9} \mathrm{O}_{6}\left([\mathrm{M}+\mathrm{H}]^{+}\right)$: 1048.5449; found: 1048.5459 .

\section{Acknowledgments}

FT acknowledges support by a Marie Curie Intra-European Fellowship within the $6^{\text {th }}$ European Community Framework Programme. We acknowledge financial support from DGA (grant $\mathrm{N}^{\circ}$.00.34.070.00.470.75.653). BKGB received a postdoctoral fellowship from the French Ministère de l'Education Nationale, de l'Enseignement Supérieur et de la Recherche. We are grateful to Prof. I. Ledoux and Prof. J. Zyss for access to EFISHG facilities. Part of the calculations was supported by the "Centre Informatique National de l'Enseignement Supérieur" (CINES-France). 


\section{References}

[1] J. R. Heath, M. A. Ratner, Physics Today 2003, 123, 43, and references therein.

[2] T. C. Lin, S. J. Chung, K. S. Kim, X. P. Wang, G. S. He, J. Swiatkiewicz, H. E. Pudavar, P. N. Prasad, in Polymers for Photonics Applications II (Eds.: K.-S. Lee), Springer-Verlag GmbH, Berlin, 2003, pp. 157-193.

[3] P. N. Prasad, B. A. Reinhardt, Chem. Mater. 1990, 2, 660-669.

[4] M. Blanchard-Desce, C. R. Physique 2002, 3, 439-448.

[5] S. R. Marder, B. Kippelen, A. K.-Y. Jen, N. Peyghambarian, Nature 1997, 388, 845851.

[6] Science 2002, 295, Special issue on Supramolecular Chemistry and Self-Assembly.

[7] C. E. Dykstra, Adv. Chem. Phys. 2003, 126, 1-40.

[8] S. Di Bella, M. A. Ratner, T. J. Marks, J. Am. Chem. Soc. 1992, 114, 5842-5849.

[9] T. Hamada, J. Chem. Phys. 1996, 100, 8777-8781.

[10] J. M. Stout, C. E. Dykstra, J. Am. Chem. Soc. 1995, 117, 5127-5132.

[11] T. Verbiest, S. Houbrechts, M. Kauranen, K. Clays, A. Persoons, J. Mater. Chem. 1997, 7, 2175-2189.

[12] B. Champagne, D. M. Bishop, Adv. Chem. Phys. 2003, 126, 41-92.

[13] A. Datta, S. K. Pati, J. Chem. Phys. 2003, 118, 8420-8427.

[14] M. Guillaume, E. Botek, B. Champagne, F. Castet, L. Ducasse, Int. J. Quantum Chem. 2002, 90, 1378-1387.

[15] M. Drobizhev, Y. Stepanenko, Y. Dzenis, A. Karotki, A. Rebane, P. N. Taylor, H. L. Anderson, J. Am. Chem. Soc. 2005, 126, 15352-15353.

[16] W.-H. Lee, H. Lee, J.-A. Kim, J.-H. Choi, M. Cho, S.-J. Jeon, B. R. Cho, J. Am. Chem. Soc. 2001, 123, 10658-10667.

[17] M. Barzoukas, M. Blanchard-Desce, J. Chem. Phys. 2000, 113, 3951-3959.

[18] F. Terenziani, A. Painelli, Phys. Rev. B 2003, 68, 165405.

[19] V. M. Agranovich, M. D. Galanin, Electronic Excitation Energy Transfer in Condensed Matter, North-Holland Publishing Company, Amsterdam, 1982.

[20] J. Knoester, in Proceedings of the International School of Physics "Enrico Fermi" 2001, Course CXLIX, Organic Nanostructures: Science and Applications (Eds.: V.M. Agranovich, G.C. La Rocca), IOS Press, The Netherlands, 2002, pp. 149-186.

[21] C. Lambert, W. Gaschler, E. Schmälzlin, K. Meerholz, C. Bräuchle, J. Chem. Soc., Perkin Trans. 2 1999, 2, 577-587.

[22] W. Leng, F. Würthner, A. Myers Kelley, J. Phys. Chem. B 2004, 108, 10284-10294.

[23] D. Beljonne, W. Wenseleers, E. Zojer, Z. Shuai, H. Vogel, S. J. K. Pond, J. W. Perry, S. R. Marder, J.-L. Brédas, Adv. Funct. Mater. 2002, 12, 631-641.

[24] C. Lambert, E. Schmälzlin, K. Meerholz, C. Bräuchle, Chem. Eur. J. 1998, 4, 512-521.

[25] A. L. Thompson, K. M. Gaab, J. Xu, C. J. Bardeen, T. J. Martínez, J. Phys. Chem. A 2004, 108, 671-682.

[26] S. Tretiak, S. Mukamel, Chem. Rev. 2002, 102, 3171-3212.

[27] C. Katan, F. Terenziani, O. Mongin, M. H. V. Werts, L. Porrès, T. Pons, J. Mertz, S. Tretiak, M. Blanchard-Desce, J. Phys. Chem. A 2005, 109, 3024-3037.

[28] E. Hendrickx, C. Boutton, K. Clays, A. Persoons, S. van Es, T. Biemans, B. Meijer, Chem. Phys. Lett. 1997, 270, 241-244.

[29] H.-J. Deussen, E. Hendrickx, C. Boutton, D. Krog, K. Clays, K. Bechgaard, A. Persoons, T. Bjørnholm, J. Am. Chem. Soc. 1996, 118, 6841-6852.

[30] M. Kauranen, T. Verbiest, C. Boutton, M. N. Teerenstra, K. Clays, A. J. Schouten, R. J. M. Nolte, A. Persoons, Science 1995, 270, 966-969. 
[31] P. J. A. Kenis, O. F. J. Noordman, S. Houbrechts, G. J. van Hummel, S. Karkema, F. C. J. M. van Veggel, K. Clays, J. F. J. Engbersen, A. Persoons, N. van Hulst, F., D. N. Reinhoudt, J. Am. Chem. Soc. 1998, 120, 7875-7883.

[32] P. J. A. Kenis, E. G. Kerver, B. H. M. Snellink-Ruël, G. van Hummel, S. Harkema, M. C. Flipse, R. H. Woudenberg, J. F. J. Engbersen, D. N. Reinhoudt, Eur. J. Org. Chem. 1998, 1089-1098.

[33] T. Verbiest, C. Samyn, C. Boutton, S. Houbrechts, M. Kauranen, A. Persoons, Adv. Mater. 1996, 8, 756-759.

[34] E. D. Rekaï, J.-B. Baudin, L. Jullien, I. Ledoux, J. Zyss, M. Blanchard-Desce, Chem. Eur. J. 2001, 7, 4395-4402.

[35] E. Kelderman, W. A. J. Starmans, J. P. M. van Duynhoven, W. Verboom, J. F. J. Engbersen, D. N. Reinhoudt, Chem. Mater. 1994, 6, 412-417.

[36] S. Yokoyama, T. Nakahama, A. Otomo, S. Mashiko, J. Am. Chem. Soc. 2000, 122, 3174-3181.

[37] H. Ma, A. K.-Y. Jen, Adv. Mater. 2001, 13, 1201-1205.

[38] E. J. H. Put, K. Clays, A. Persoons, T. Biemans, C. P. M. Luijkx, E. W. Meijer, Chem. Phys. Lett. 1996, 260, 136-141.

[39] E. Brouyère, A. Persoons, J.-L. Brédas, J. Phys. Chem. A 1997, 101, 4142-4148.

[40] G. P. Bartholomew, G. C. Bazan, J. Am. Chem. Soc. 2002, 124, 5183-5196.

[41] G. P. Bartholomew, I. Ledoux, S. Mukamel, G. C. Bazan, J. Zyss, J. Am. Chem. Soc. 2002, 124, 13480-13485.

[42] A. Painelli, F. Terenziani, L. Angiolini, T. Benelli, L. Giorgini, Chem. Eur. J. in press.

[43] J. N. Demas, G. A. Crosby, Journal of Physical Chemistry 1971, 75, 991-1024.

[44] P. Debye, Polar Molecules, Dover, New York, 1945.

[45] B. F. Levine, C. G. Bethea, J. Chem. Phys. 1975, 63, 2666-2682.

[46] J. L. Oudar, D. S. Chemla, J. Chem. Phys. 1977, 66, 2664-2668.

[47] A. Willetts, J. E. Rice, D. M. Burland, D. P. Shelton, J. Chem. Phys. 1992, 97, 75907599.

[48] C. Reichardt, Chem. Rev. 1994, 94, 2319-2358.

[49] B. Boldrini, E. Cavalli, A. Painelli, F. Terenziani, J. Phys. Chem. A 2002, 106, 62866294.

[50] A. Painelli, F. Terenziani, Chem. Phys. Lett. 1999, 312, 211-220.

[51] M. M. Tautounji, M. A. Ratner, J. Phys. Chem. A 2000, 104, 8566-8569.

[52] Spectra have been calculated without accounting for the inhomogeneous broadening effect due to the solvent. This has no influence on the position and integrated intensity of the bands.

[53] For dimers and trimer of Series II dipole moments have not been measured.

[54] A. Painelli, F. Terenziani, J. Am. Chem. Soc. 2003, 125, 5624-5625.

[55] F. Terenziani, A. Painelli, J. Lumin. 2004, 112, 474-478.

[56] F. Terenziani, A. Painelli, A. Girlando, R. M. Metzger, J. Phys. Chem. B 2004, 108, 10743-10750.

[57] R. S. Mulliken, J. Am. Chem. Soc. 1952, 74, 811-824.

[58] A. Painelli, F. Terenziani, J. Phys. Chem. A 2000, 104, 11041-11048.

[59] L. Del Freo, F. Terenziani, A. Painelli, J. Chem. Phys. 2002, 116, 755-761.

[60] For calculations presented in this paper 8 vibrational states are enough to converge results in Series II, while at least 18 vibrational states are needed for calculating spectra of Series I; this is due to the much greater vibrational relaxation energy for the chromophore of Series I than for the chromophore of Series II.

[61] G. D. Scholes, Annu. Rev. Phys. Chem. 2003, 54, 57-87.

[62] D. A. Kleinman, Phys. Rev. 1962, 126, 1977-1979. 
[63] While for spectra of products of Series I 8 vibrational states are not enough, they lead to converged results for ground state properties.

[64] M. Mladenova, L. Ventelon, M. Blanchard-Desce, Tetrahedron Lett. 1999, 40, 69236926. 


\section{Legends}

Table 1. Absorption and fluorescence properties of I-1 and II-1 in different solvents: maximum absorption wavelength $\left(\lambda_{\text {abs }}\right)$, oscillator strength $(f)$, emission wavelength $\left(\lambda_{\mathrm{em}}\right.$, on the maximum), fluorescence quantum yield $(\phi)$.

Table 2. Absorption and fluorescence properties of analogue products from Series I and from Series II in $\mathrm{CHCl}_{3}$ : maximum absorption wavelength $\left(\lambda_{\mathrm{abs}}\right)$, oscillator strength $(f)$, emission wavelength $\left(\lambda_{\mathrm{em}}\right.$, on the maximum), fluorescence quantum yield $(\phi)$.

Table 3. Parameters of the two-state model (see text) that allow reproducing experimental absorption and fluorescence spectra of I-1 and II-1. The three values for $\varepsilon_{o r}$ correspond to toluene, $\mathrm{CHCl}_{3}$ and acetone, respectively, for $\mathbf{I}-\mathbf{1}$ and to toluene, $\mathrm{CHCl}_{3}$ and DMSO, respectively, for II-1. Units: $\mathrm{eV}$.

Table 4. Dipole moments and hyperpolarisabilities of all products of Series I and some products of Series II. The last two columns report calculated values. Values in parenthesis correspond to the ratio between the response of the relevant multimer and the response of the monomer.

Figure 1. Compounds of Series I.

Figure 2. Compounds of Series II.

Figure 3. Absorption and fluorescence solvatochromism of the monomeric models: (a) I-1; (b) II-1.

Figure 4. Absorption (per sub-chromophore) and fluorescence spectra in chloroform: (a) products of Series I; (b) products of Series II.

Figure 5. Schematic representation of the supramolecular structures. Spring-like lines correspond to the linkers between the central core and the active sub-chromophores. Sub-chromophores are represented by rods bearing electron-donor (D) and electron-acceptor (A) ends. For dimers and trimers $\mathrm{C}_{2 \mathrm{v}}$ and $\mathrm{C}_{3 \mathrm{v}}$ symmetries are assumed, respectively; $\alpha$ is the angle formed by each sub-chromophore with respect to the main symmetry axis (dashed line).

Figure 6. Calculated absorption and fluorescence solvatochromism of the monomeric models: (a) I-1; (b) II-1. Parameters in Table 3 have been used.

Figure 7. Calculated absorption spectra (per sub-chromophore) of the products of Series II (chloroform). Parameters in Table 3 have been used. For II-3 inhomogeneous broadening has not been accounted for and a half-width at half-maximum of $0.11 \mathrm{eV}$ has been imposed.

Figure 8. Angle- and distance dependence of the SHG figure of merit, calculated for a dimer $\left(\mathrm{C}_{2 \mathrm{v}}\right.$ symmetry) of (a) $\mathrm{C}_{16} \mathrm{H}_{33} \mathrm{Q}-3 \mathrm{CNQ}$ molecules in $\mathrm{CHCl}_{3}$ (parameters estimated in Ref. ${ }^{[56]}$ ); (b) molecules being in the cyanine limit when isolated.

Scheme 1. Synthesis of graftable chromophoric bricks 3 and $\mathbf{6 b}$. a) 2, EtOH, reflux, 18 h; b) dihydropyran, PPTS, $\mathrm{CH}_{2} \mathrm{Cl}_{2}, 2{ }^{\circ} \mathrm{C}, 15 \mathrm{~h}$; c) 5, NaH, THF, $20{ }^{\circ} \mathrm{C}, 16 \mathrm{~h}$; d) $\mathrm{HCl}, \mathrm{CH}_{2} \mathrm{Cl}_{2} / \mathrm{EtOH}$, reflux, $17 \mathrm{~h}$.

Scheme 2. Synthesis of the two series of multichromophoric assemblies. Reaction conditions: $\mathrm{NEt}_{3}$, $\mathrm{CH}_{2} \mathrm{Cl}_{2}, 20{ }^{\circ} \mathrm{C}, 4 \mathrm{~h}$, then reflux, $1 \mathrm{~h}$. 


\section{Tables and Figures}

Table 1. Absorption and fluorescence properties of I-1 and II-1 in different solvents: maximum absorption wavelength $\left(\lambda_{\mathrm{abs}}\right)$, oscillator strength $(f)$, emission wavelength $\left(\lambda_{\mathrm{em}}\right.$, on the maximum), fluorescence quantum yield $(\phi)$.

\begin{tabular}{llcccc}
\hline & Solvent & $\boldsymbol{\lambda}_{\text {abs }}[\mathrm{nm}]$ & $\boldsymbol{f}$ & $\boldsymbol{\lambda}_{\text {em }}[\mathrm{nm}]$ & $\boldsymbol{\phi}$ \\
\hline \multirow{3}{*}{ I-1 } & Toluene & 433 & 1.6 & 585 & 0.84 \\
& $\mathrm{CHCl}_{3}$ & 440 & 1.6 & 750 & 0.031 \\
& Acetone & 439 & 1.7 & 775 & 0.015 \\
\hline \multirow{3}{*}{ II-1 } & Toluene & 425 & 1.6 & 450 & 0.001 \\
& $\mathrm{CHCl}_{3}$ & 433 & 2.0 & 465 & 0.002 \\
& $\mathrm{DMSO}$ & 440 & 2.1 & 490 & 0.004 \\
\hline
\end{tabular}

Table 2. Absorption and fluorescence properties of analogue products from Series I and from Series II in $\mathrm{CHCl}_{3}$ : maximum absorption wavelength $\left(\lambda_{\text {abs }}\right)$, oscillator strength $(f)$, emission wavelength $\left(\lambda_{\text {em }}\right.$, on the maximum), fluorescence quantum yield $(\phi)$.

\begin{tabular}{lcccc}
\hline Product & $\boldsymbol{\lambda}_{\text {abs }}[\mathrm{nm}]$ & $\boldsymbol{f}$ & $\boldsymbol{\lambda}_{\text {em }}[\mathrm{nm}]$ & $\boldsymbol{\phi}$ \\
\hline I-1 & 440 & 1.6 & 750 & 0.031 \\
I-2O & 438 & 3.2 & 745 & 0.036 \\
I-2P & 436 & 3.3 & 740 & 0.025 \\
I-3 & 438 & 4.8 & 735 & 0.032 \\
\hline II-1 & 433 & 2.0 & 465 & 0.002 \\
II-2M & 430 & 4.0 & 465 & 0.002 \\
II-2P & 430 & 3.8 & 465 & 0.002 \\
II-3 & 430 & 5.1 & 470 & 0.004 \\
\hline
\end{tabular}

Table 3. Parameters of the two-state model (see text) that allow reproducing experimental absorption and fluorescence spectra of I-1 and II-1. The three values for $\varepsilon_{o r}$ correspond to toluene, $\mathrm{CHCl}_{3}$ and acetone, respectively, for I-1; to toluene, $\mathrm{CHCl}_{3}$ and DMSO, respectively, for II-1. Units: $\mathrm{eV}$.

\begin{tabular}{cccccccc}
\hline & $\boldsymbol{z}_{\mathbf{0}}$ & $\sqrt{\mathbf{2} t}$ & $\boldsymbol{\omega}_{\boldsymbol{v}}$ & $\boldsymbol{\varepsilon}_{\boldsymbol{v}}$ & $\boldsymbol{\Gamma}$ & $\boldsymbol{\varepsilon}_{\boldsymbol{o r}}$ & $\boldsymbol{\varepsilon}_{\boldsymbol{c}}$ \\
\hline $\mathbf{I}-\mathbf{1}$ & 1.3 & 0.6 & 0.12 & 0.52 & 0.06 & $0 / 0.35 / 0.40$ & 0.15 \\
$\mathbf{I I}-1$ & 1.0 & 1.1 & 0.16 & 0.21 & 0.05 & $0.16 / 0.27 / 0.43$ & $/$ \\
\hline
\end{tabular}


Table 4. Dipole moments and hyperpolarisabilities of all products of Series I and some products of Series II. The last two columns report calculated values. Values in parenthesis correspond to the ratio between the response of the relevant multimer and the response of the monomer.

\begin{tabular}{|c|c|c|c|c|c|c|}
\hline Product & $\begin{array}{c}\mu \\
{[\mathrm{D}]}\end{array}$ & $\begin{array}{c}\mu \beta(2 \omega) \\
{\left[10^{-48} \mathrm{esu}\right]}\end{array}$ & 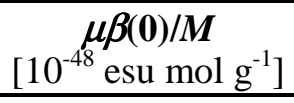 & $\begin{array}{c}\beta(\mathbf{2} \boldsymbol{\omega}) \\
{\left[10^{-30} \mathrm{esu}\right]}\end{array}$ & $\begin{array}{l}\mu \beta(2 \omega)^{(\text {calc })} \\
{\left[10^{-48} \mathrm{esu}\right]}\end{array}$ & $\begin{array}{l}\boldsymbol{\beta}(\mathbf{2} \boldsymbol{\omega}){ }^{(\mathrm{calc})} \\
{\left[10^{-30} \mathrm{esu}\right]}\end{array}$ \\
\hline I-1 & 8.7 & 390 & 0.61 & 45 & 258 & 153 \\
\hline I-2O & $12.3(1.4)$ & $720(1.8)$ & 0.62 & $58(1.3)$ & 488 (1.9) & 209 (1.4) \\
\hline I-2M & $14.2(1.6)$ & $790(2.0)$ & 0.68 & $56(1.2)$ & $578(2.2)$ & $228(1.5)$ \\
\hline I-2P & $13.2(1.5)$ & $900(2.3)$ & 0.77 & $68(1.5)$ & $632(2.4)$ & 239 (1.6) \\
\hline I-3 & $15.1(1.7)$ & $1260(3.2)$ & 0.75 & $83(1.8)$ & $733(2.8)$ & $255(1.7)$ \\
\hline II-1 & 9.7 & 180 & 0.35 & 19 & 214 & 67 \\
\hline II-2M & I & 350 (1.9) & 0.36 & I & $544(2.5)$ & 107 (1.6) \\
\hline II-3 & I & $715(4.0)$ & 0.52 & I & $831(3.9)$ & $130(1.9)$ \\
\hline
\end{tabular}



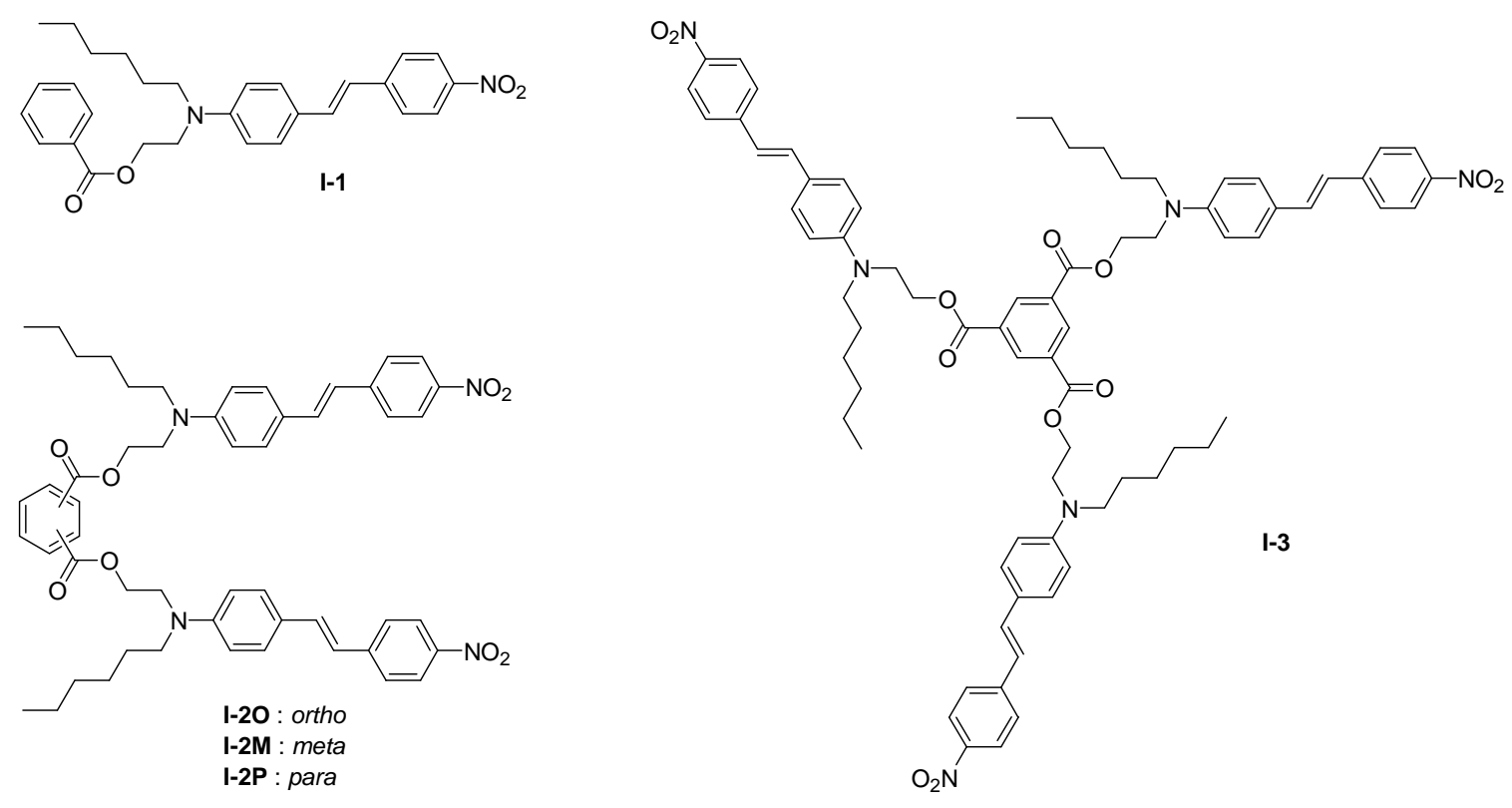

Figure 1. Compounds of Series I.
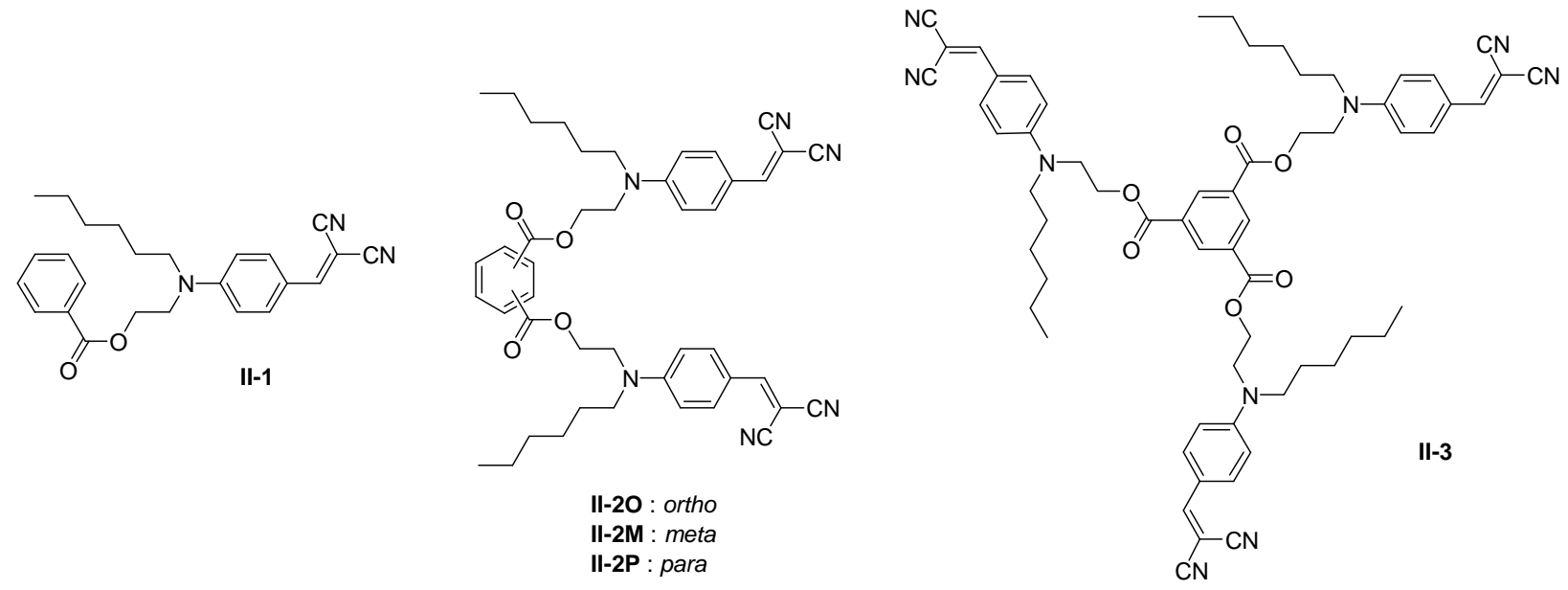

Figure 2. Compounds of Series II. 


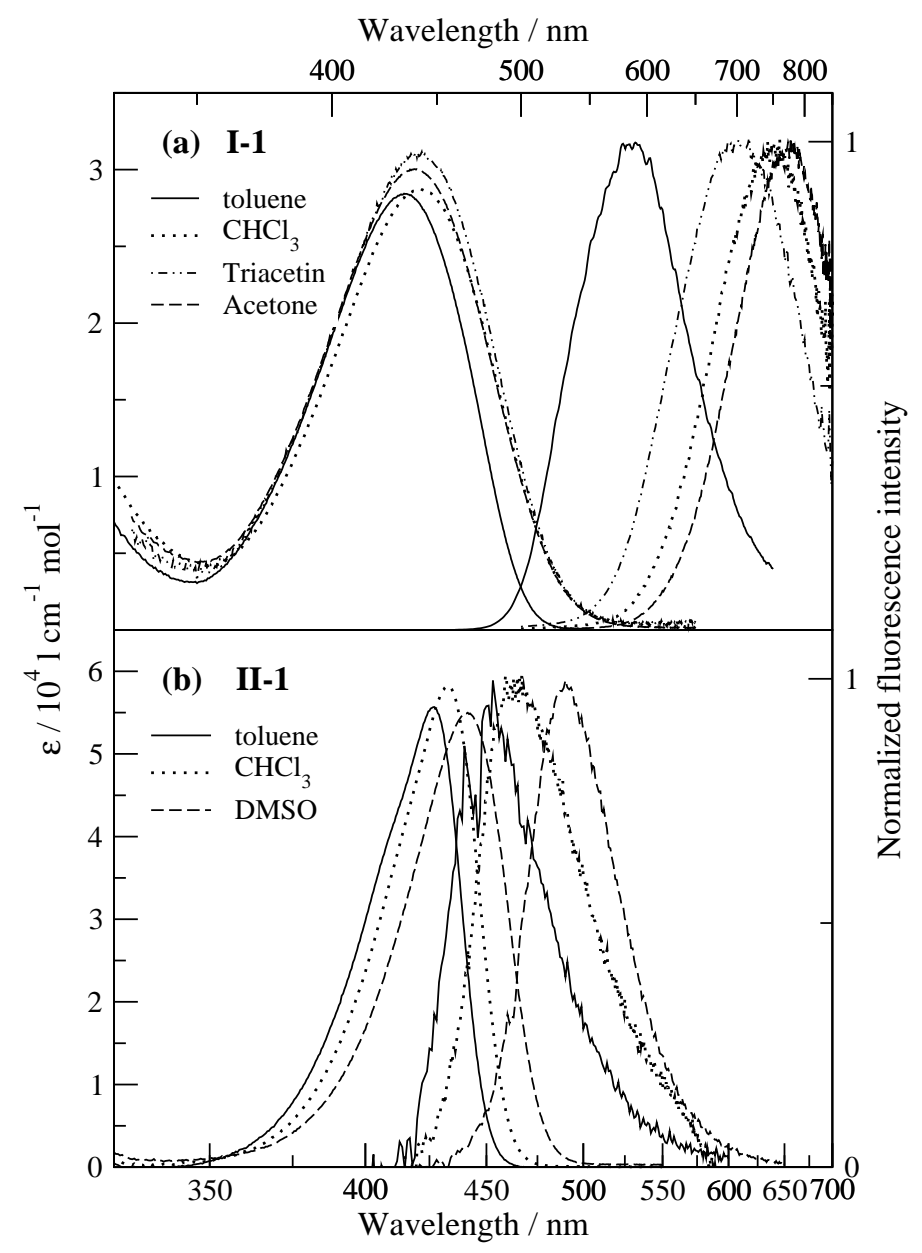

Figure 3. Absorption and fluorescence solvatochromism of the monomeric models: (a) I-1; (b) II-1. 


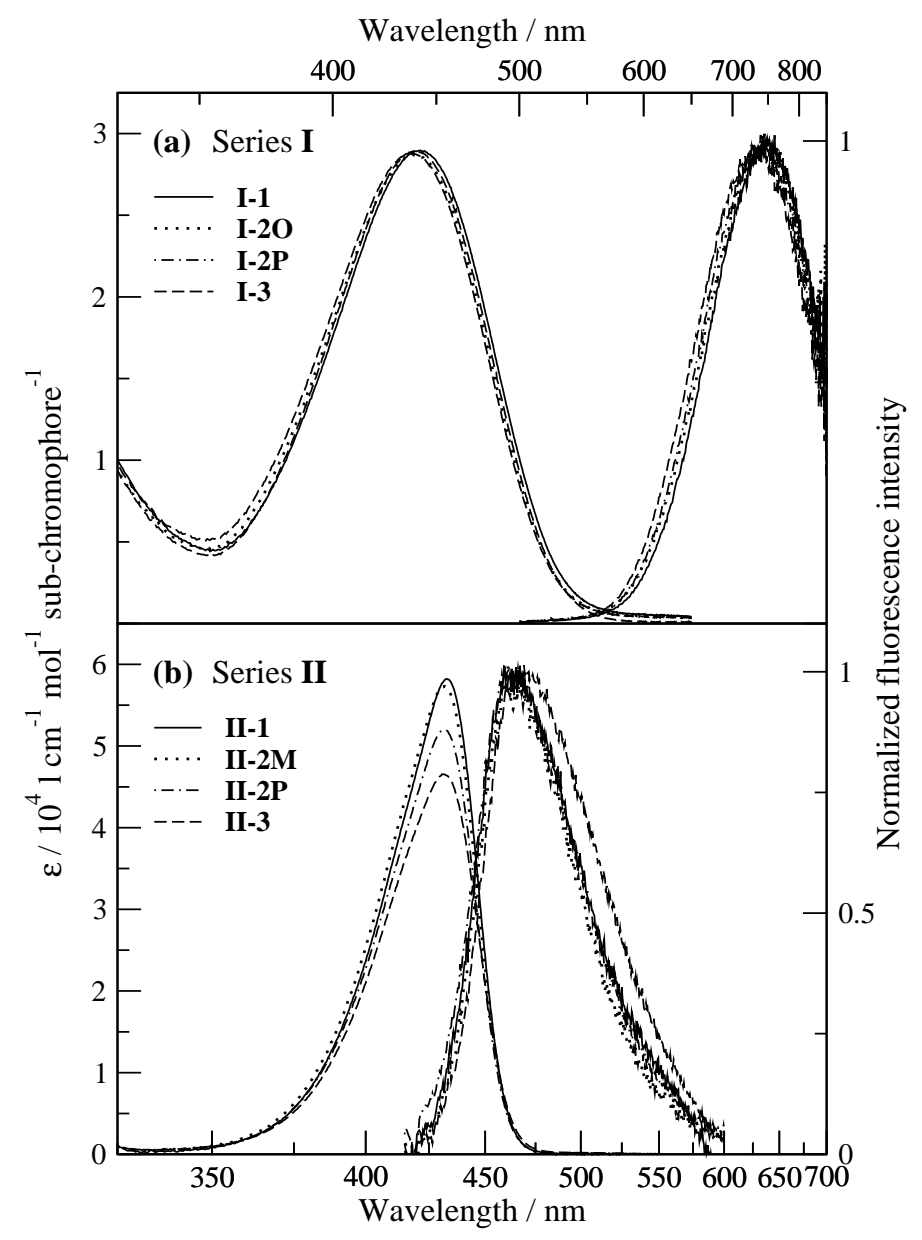

Figure 4. Absorption (per sub-chromophore) and fluorescence spectra in chloroform: (a) products of Series I; (b) products of Series II.
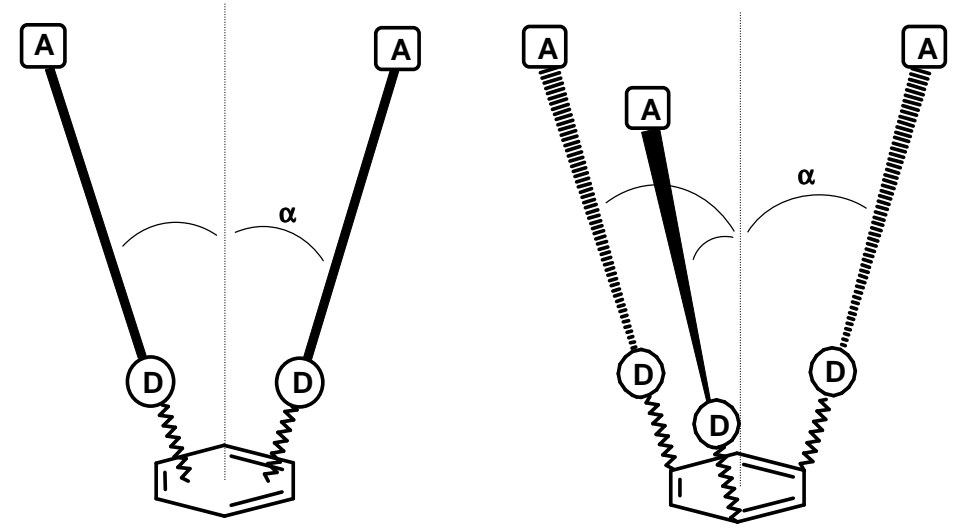

Figure 5. Schematic representation of the supramolecular structures. Spring-like lines correspond to the linkers between the central core and the active sub-chromophores. Sub-chromophores are represented by rods bearing electron-donor (D) and electron-acceptor (A) ends. For dimers and trimers $\mathrm{C}_{2 \mathrm{v}}$ and $\mathrm{C}_{3 \mathrm{v}}$ symmetries are assumed, respectively; $\alpha$ is the angle formed by each sub-chromophore with respect to the main symmetry axis (dashed line). 


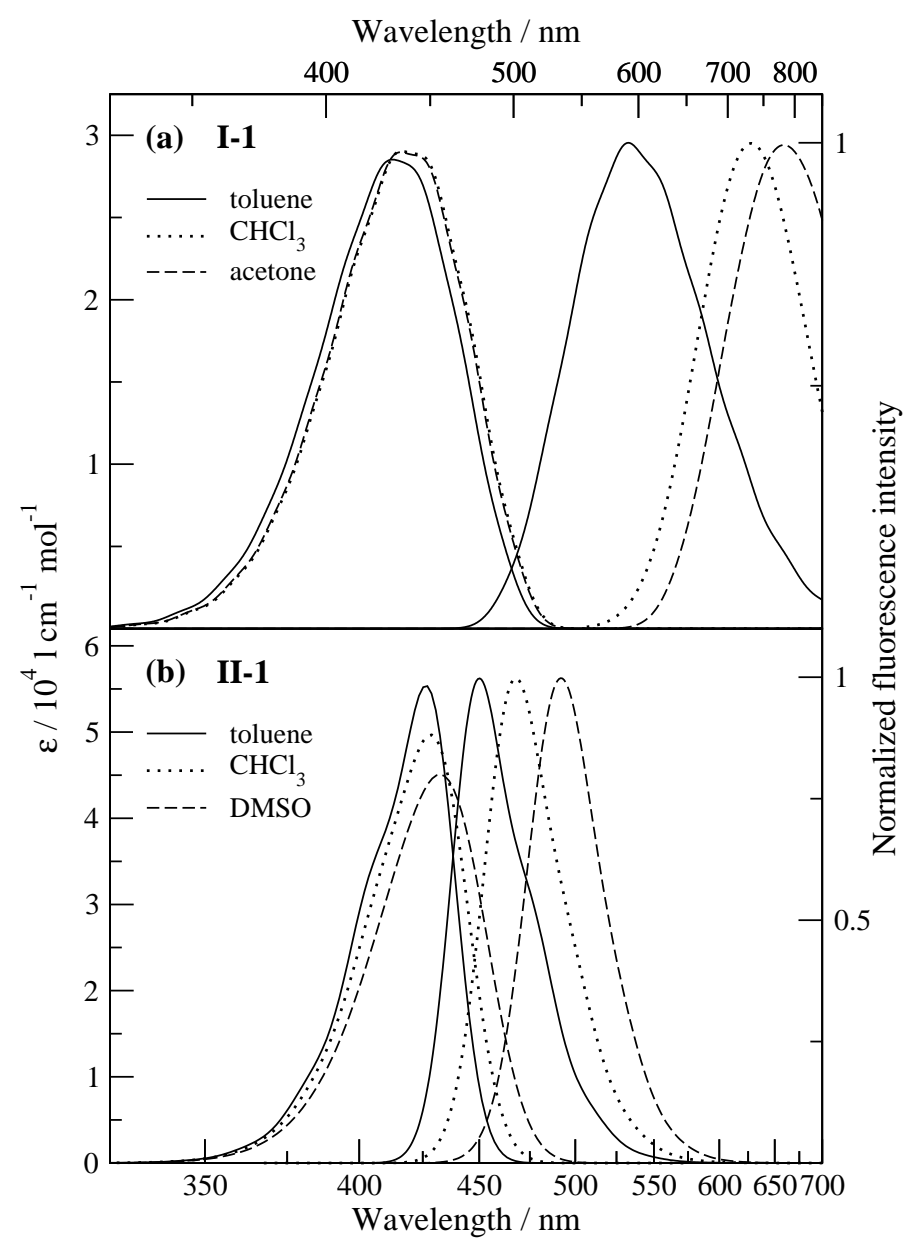

Figure 6. Calculated absorption and fluorescence solvatochromism of the monomeric models: (a) I-1; (b) II-1. Parameters in Table 3 have been used.

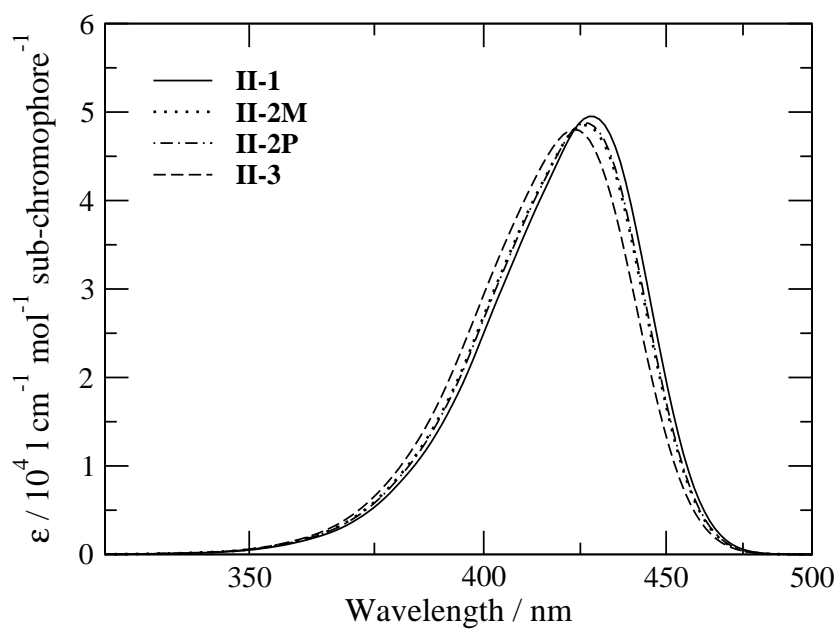

Figure 7. Calculated absorption spectra (per sub-chromophore) of the products of Series II (chloroform). Parameters in Table 3 have been used. For II-3 inhomogeneous broadening has not been accounted for and a half-width at half-maximum of $0.11 \mathrm{eV}$ has been imposed. 

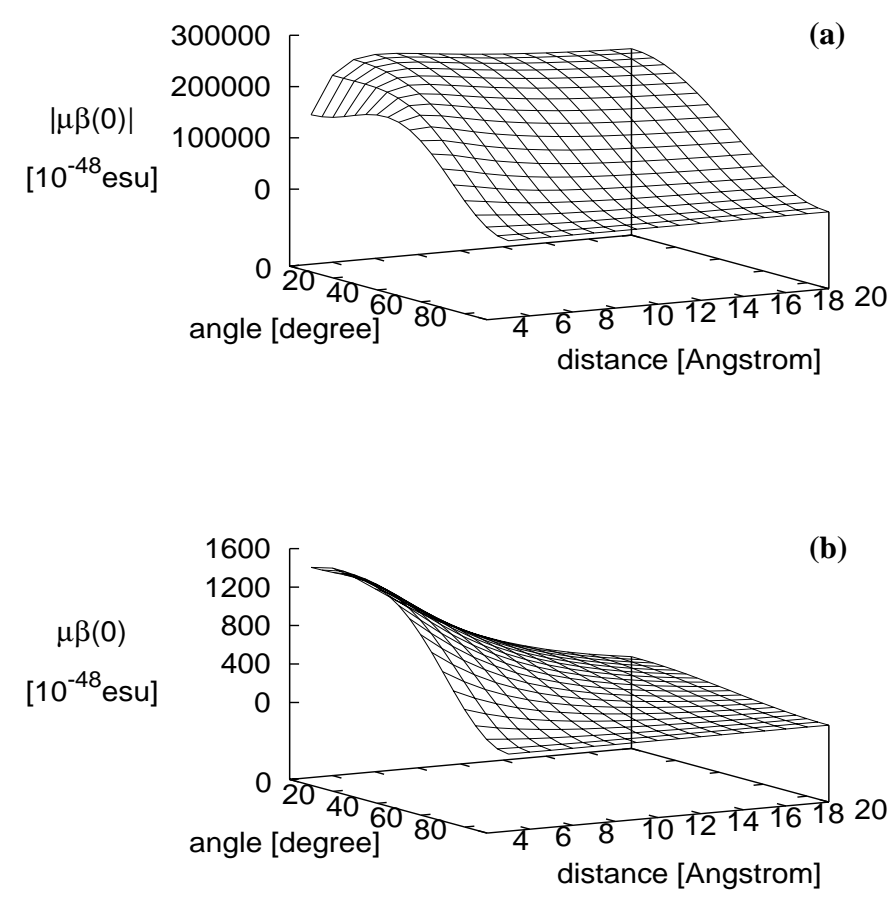

Figure 8. Angle- and distance dependence of the SHG figure of merit, calculated for a dimer $\left(\mathrm{C}_{2 \mathrm{v}}\right.$ symmetry) of (a) $\mathrm{C}_{16} \mathrm{H}_{33} \mathrm{Q}-3 \mathrm{CNQ}$ molecules in $\mathrm{CHCl}_{3}$ (parameters estimated in $\operatorname{Ref}{ }^{\left[{ }^{[5]}\right.}$ ); (b) molecules being in the cyanine limit when isolated.

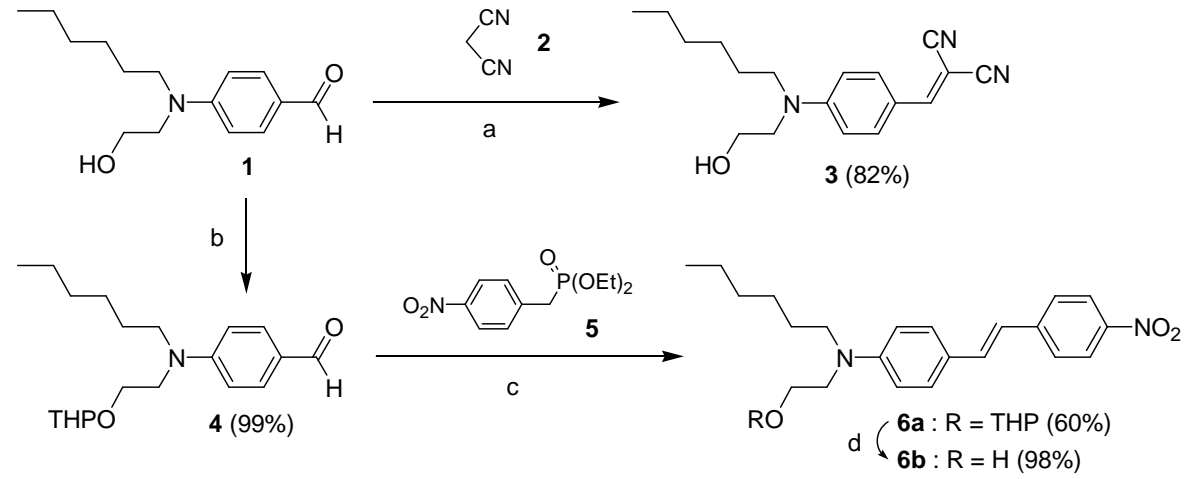

Scheme 1. Synthesis of graftable chromophoric bricks 3 and $\mathbf{6 b}$. a) 2, EtOH, reflux, 18 h; b) dihydropyran, PPTS, $\mathrm{CH}_{2} \mathrm{Cl}_{2}, 20{ }^{\circ} \mathrm{C}, 15 \mathrm{~h}$; c) 5, NaH, THF, $20{ }^{\circ} \mathrm{C}, 16 \mathrm{~h}$; d) $\mathrm{HCl}, \mathrm{CH}_{2} \mathrm{Cl}_{2} / \mathrm{EtOH}$, reflux, $17 \mathrm{~h}$. 


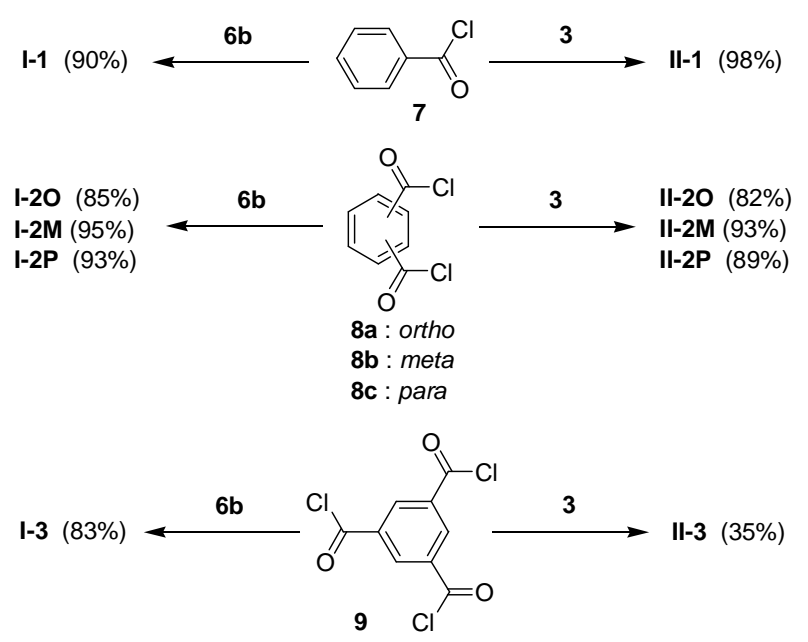

Scheme 2. Synthesis of the two series of multichromophoric assemblies. Reaction conditions: $\mathrm{NEt}_{3}$, $\mathrm{CH}_{2} \mathrm{Cl}_{2}, 2{ }^{\circ} \mathrm{C}, 4 \mathrm{~h}$, then reflux, $1 \mathrm{~h}$. 


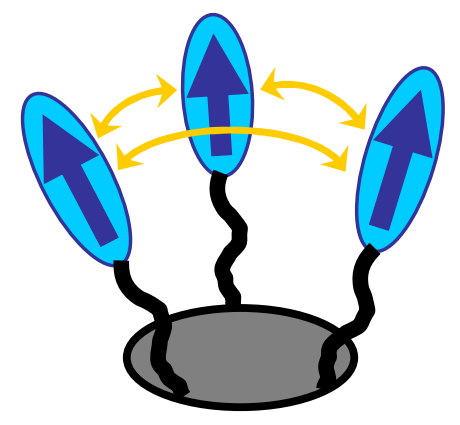

Multichromophoric systems obtained by grafting dipolar units have been synthesised and investigated. A non-random spatial organisation of sub-chromophores is spontaneously obtained in the assemblies due to interchromophore interactions. This is the origin of net dipole moments and increased SHG figures of merit with respect to the monomer. Polarisability effects in these and other nanoassemblies are investigated through a theoretical model for interacting polar and polarisable chromophores. 